\title{
De pueblos a barrios: reconfiguraciones espaciales y administrativas en la frontera sur de la isla de México-Tenochtitlan durante las décadas de 1550 y 1560*
}

\section{Resumen}

En el presente artículo se discuten las transformaciones que experimentaron, en el límite sur de la antigua isla de Tenochtitlan, la espacialidad y las zonas de liminalidad colectiva de la época prehispánica cuando estas se orientaron hacia las nuevas modalidades de territorialidad y de fijación fronteriza institucionalizada y que definieron a la república de indios afincada en su heredera virreinal -la Ciudad de México- desde el siglo XVI. Mediante la colecta y la sistematización de un amplio espectro de fuentes archivísticas, documentales y bibliográficas, se somete a examen el cambio taxonómico en la condición administrativa de cuatro centros poblacionales meridionales con carácter conurbano: Toltenco, Zoquipan, Mixiuhcan e Iztacalco. En este sentido, se analiza la conjunción entre los intereses tributarios de la elite indígena cabildante de la ciudad, la superación de catástrofes ecológicas y la agencia política ofrecida por la Orden de San Francisco.

Palabras clave: México-Tenochtitlan, altepetl prehispánico, comunidad de naturales, territorialidad virreinal, franciscanos.

Referencia para citar este artículo: ROVIRA MORGADO, Rossend (2016). "De pueblos a barrios: reconfiguraciones espaciales y administrativas en la frontera sur de la isla de México-Tenochtitlan durante las décadas de 1550 y 1560”. En Anuario de Historia Regional y de las Fronteras. 21 (1). pp. 15-49.

Rossend Rovira Morgado: Becario del Programa de Becas Posdoctorales de la Coordinación de Humanidades. Centro de Investigaciones sobre América Latina y El Caribe. Investigador visitante. Universidad Nacional Autónoma de México. Correo electrónico: rroviramorgado@hotmail.com.

\footnotetext{
* Artículo de investigación, resultado del proyecto de investigación posdoctoral Influjo y patronazgo franciscano en los cabildos indios virreinales de Hispanoamérica: Un estudio analítico-comparativo para San Juan Tenochtitlan (Nueva España) y el Cusco (Perú), en el siglo XVI. Se encuentra bajo la asesoría académica de la Dra. Patricia Escandón Bolaños (Universidad Autónoma de México) y está siendo realizado, entre marzo de 2015 y marzo de 2016, en el Centro de Investigaciones sobre América Latina y El Caribe de la Universidad Nacional Autónoma de México. El proyecto es financiado por el Programa de Becas Posdoctorales de la Coordinación de Humanidades de la Universidad Nacional Autónoma de México.
} 


\title{
From Towns to Neighborhoods: Space and Administrative Reconfiguration in the Schemes Southern Border of the Mexico-Tenochtitlan Island in the 1550's and 1560's
}

\begin{abstract}
This article analyzes the transformations of the southern border of the ancient Tenochtitlan Island in terms of spatiality and collective liminality zones in pre-hispanic times when these changes were oriented toward new territorial modalities and institutional border determination. These characteristics defined the Republic of Indians that was settled amidst the viceroy territory (Mexico City) from the $16^{\text {th }}$ century. Collection and systematization of a broad range of archive, document, and bibliographic sources resulted in the taxonomic change of the administration status for four southern population centers with conurbation characteristics: Toltenco, Zoquipan, Mixiuhcan and Iztacalco. The conjunction among tax interests of the elite indigenous members of the city Cabildo, the overcoming of ecological catastrophes, and the political agency offered by the Saint Francis Order.
\end{abstract}

Keywords: México-Tenochtitlan, pre-hispanic altepetl, community of naturals, viceroy territoriality, the franciscan order.

\section{De povoados a bairros: reconfigurações espaciais e administrativas na fronteira sul da ilha de México-Tenochtitlan durante as décadas de 1550 e 1560}

\section{Resumo}

No presente artigo são discutidas as transformações que experimentaram, no limite sul da antiga ilha de Tenochtitlan, a espacialidade e as zonas de liminar coletiva da época préhispânica, quando estas se orientaram em direção a novas modalidades de territorialidade $e$ de demarcação fronteiriça institucionalizada e que definiram a república de indios estabelecida em sua herdeira vice-real-a Cidade do México-desde o século XVI. Mediante a coleta e a sistematização de um amplo espectro de fontes arquivistas, documentais e bibliográficas, é submetida a exame a mudança taxonômica na condição administrativa de quatro centros populacionais meridionais com caráter com urbano: Toltenco, Zoquipan, Mixiuhcan e Iztacalco. Nesse sentido, se analisa a conjunção entre os interesses tributários da elite indígena regente da cidade, a superação de catástrofes ecológicas e a agência politica oferecida pela Ordem de São Francisco.

Palavras-chave: México-Tenochtitlan, altepetl pré-hispânico, comunidade de nativos, territorialidade vice-real, franciscanos. 


\section{Introducción}

A pesar de que la ciudad México-Tenochtitlan ha sido, es y será un campo fecundo para la investigación, su región comarcana aledaña no ha recibido el mismo grado de atención intelectual. Poco sabemos del conjunto de asentamientos de baja y de media densidad demográfica que, antes del proceso de conquista que Hernán Cortés y de que sus huestes iniciasen en 1520, integraban este hinterland más inmediato. Y mucho es lo que continuamos ignorando también acerca de las relaciones espaciales establecidas, si realmente existía una división física o demarcatoria clara entre lo urbano y lo rural -tal y como lo presuponemos desde una óptica ontológica occidental-, o si la identidad colectiva de los que vivían dentro de la isla se circunscribía solo a ella o se desplegaba hacia los sitios circundantes. Si todas estas dudas asoman para el período precolombino, las primeras décadas que siguieron a la Conquista no parecen ofrecer tampoco un panorama más esperanzador. Desde 1524, la isla de México, con sus dos ciudades -una indígena y otra española-, continuaba sustentándose en estos núcleos poblacionales satelitales. Pero las nuevas dinámicas generadas con el establecimiento del orden novohispano habrían tendido a modular las relaciones no solo entre peninsulares y la comunidad amerindia, sino también entre los diferentes sectores de una sociedad indígena nahua que si ya era compleja antes de 1519, lo continuó siendo después. El presente artículo contribuye con un acercamiento al estudio de las complejas interacciones que desde la etapa precortesiana hasta el Virreinato temprano se establecieron en el límite y la frontera sur de la isla de México.

Figura 1. Isla de México en la época prehispánica tardía y en el Virreinato temprano con la localización de los sitios que se discuten en este trabajo.

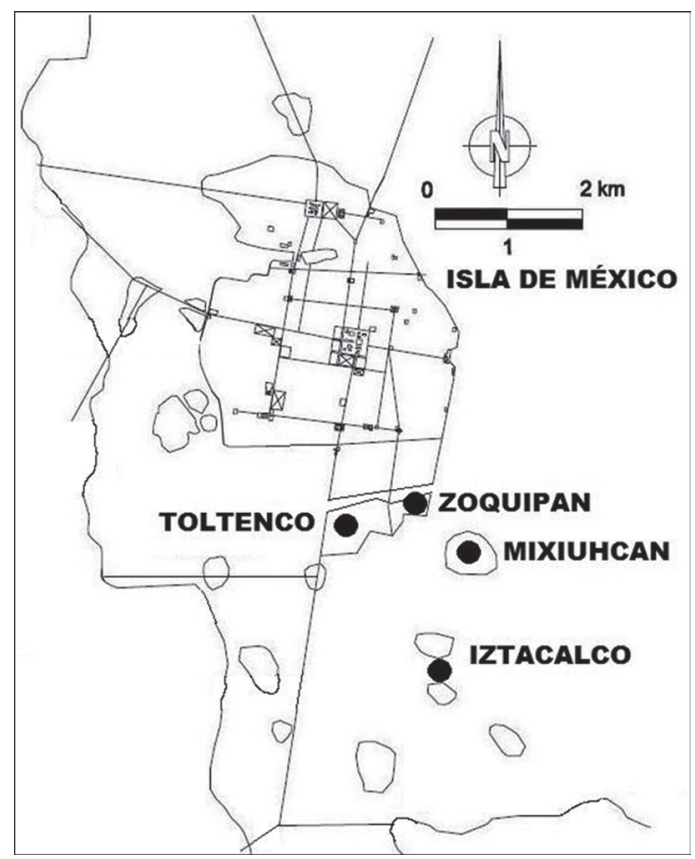

Fuente: diseño del autor en base a los datos contenidos en González Aparicio, 1973. 


\section{El punto de partida: La isla de México y su altepetl en la época prehispánica tardía}

Resulta pertinente iniciar nuestro estudio con una serie de consideraciones preliminares. El carácter insular de la antigua Tenochtitlan-Tlatelolco -enclavada en el sistema lacustre de la Cuenca de México- es irrefutable y ha estimulado múltiples investigaciones modernas relativas a su configuración morfológica y demografía ${ }^{1}$, así como a sus complejas estructuras y a su organización sociolaboral ${ }^{2}$. Los cálculos poblacionales basculan entre un mínimo de 85.000 y un máximo de entre 200.000 y 300.000 habitantes $^{3}$. La superficie urbana pudo situarse entre 11,5 y $16 \mathrm{~km}^{2}$. El paleo-paisaje urbano de la actual Ciudad de México estuvo constituido, en origen, por una serie de islotes que sobresalían poco de la superficie del lago, ubicado a casi 2.240 metros de altitud ${ }^{4}$. Estas pequeñas islas estaban formadas por amontonamientos sedimentarios de origen clástico y arenoso -o tlateles- depositados por encima de los estratos geológicos, de entre los cuales sobresale la bentonita ${ }^{5}$. El espacio entre estos islotes estaba ocupado por carrizales y espadañas acuáticas que fueron después desbrozados mediante complejas técnicas de drenaje y quema extensiva ${ }^{6}$. El perímetro de este primigenio espacio insular se cerró mediante la acumulación sucesiva de tierra y de escombros, hecho que posibilitó la ampliación del suelo urbanizable. La habitabilidad de este segundo cinturón urbano se consiguió con numerosos terraplenes, plataformas y apisonados cimentados en pilotajes que proporcionaban basculación y flotabilidad a las estructuras arquitectónicas mediante la proyección de la presión ejercida hacia el nivel geológico ${ }^{7}$. La inclinación natural del terreno hacia el este -que actuó como conductor de aguas hacia el vaso del Lago de Texcoco- condicionó la hidrología urbana de Tenochtitlan-Tlatelolco.

Varias fueron las corrientes de agua que fluyeron desde las sierras y las cordilleras situadas al oeste del valle por las inmediaciones y por el interior mismo de la ciudad. Los naturales optimizaron estos recursos hídricos, conduciendo y canalizando dichos ríos en acequias urbanas que nutrieron a zanjas y a arterias acuáticas menores. Un intrincado sistema de puertas, contrapuertas, diques y albarradas ayudó a obtener un manejo eficiente de las aguas y también, fortaleció el control de estas en caso de inundación ${ }^{8}$. Gracias a este inteligente dominio, los mexicas pudieron solucionar problemas asociados al incremento demográfico mediante la construcción de amplios distritos chinamperos ${ }^{9}$.

\footnotetext{
${ }^{1}$ Toussaint, et al. 1938; Cook y Simpson, 1948, pp. 30-34; Calnek, 1972, pp. 104-115; González Aparicio, 1973; Lombardo de Ruiz, 1973, pp.120 y ss.; Bernal, 1984 (1974), pp. 14, 123 y ss.; García Quintana y Romero Galván, 1978, pp. 51-122; Sanders, et al. 1979, p. 163; Sanders, 2003, p. 214; Smith, 2005, p. 411.

${ }^{2}$ Calnek, 1974, 1976, pp. 287-292; Rojas Gutiérrez de Gandarilla, 1986, 2012; Mundy, 2015.

${ }^{3}$ Rojas Gutiérrez de Gandarilla, 1986, pp. 275-276; González Rul, 1988; Sánchez Vázquez. et al. 2007, p. 182.

${ }^{4}$ Carrera Stampa, 1949; González Rul, 1998, pp. 23 y 39; Sánchez Vázquez, et al. 2007, p. 148 (Figura 1), 149; Sanders, et al. 1979, p. 78.

${ }^{5}$ Zeevaert, 1957; Díaz-Rodríguez, 2006, p. 126; Sánchez Vázquez, et al. 2007, pp. 69 y 117.

${ }^{6}$ García Quintana y Romero Galván, 1978, pp. 58-59.

${ }^{7}$ Sánchez Vázquez, et al. 2007; Rovira Morgado, 2012, pp. 35-36.

${ }^{8}$ Palerm (ed.), 1973; Rojas Rabiela, et al. 1974; Villalonga, 2007, pp. 78-91.

${ }^{9}$ Recordamos que la chinampa era una parcela de terreno ganada al lago mediante la acumulación de detritus, escombros y tierras fangosas. Se utilizaba como terreno agrario y/o habitacional.
} 
En efecto: un exhaustivo análisis textual y pictográfico de fuentes archivísticas datadas en el siglo XVI, permitió a Edward E. Calnek afirmar que esta tercera corona urbana habría estado integrada por parcelas domésticas chinamperas cuya superficie osciló habitualmente entre los 100 y $850 \mathrm{~m}^{210}$.

Es más: la sección sureste de México-Tenochtitlan habría concentrado las mayores extensiones chinamperas ${ }^{11}$. En su fracción más meridional-zona de nuestro estudio-los lotes y las parcelas pudieron sobrepasar fácilmente los 4.000 o $5.000 \mathrm{~m}^{212}$, superficie que recuerda a parcelarios rurales ${ }^{13}$. Ciertos econichos urbanos marginales, poco favorables para la concentración poblacional, parecen haber sido característicos de varias zonas periféricas de la ciudad. La existencia de ciénagas, de lagunillas y de amplias extensiones de carrizales y de tulares se documenta tanto en fuentes históricas y cartográficas del Virreinato como en reconocimientos arqueológicos contemporáneos ${ }^{14}$ (Figura 2).

Figura 2. Características edáficas y ecológicas presentes en la isla de Tenochtitlan-Tlatelolco.

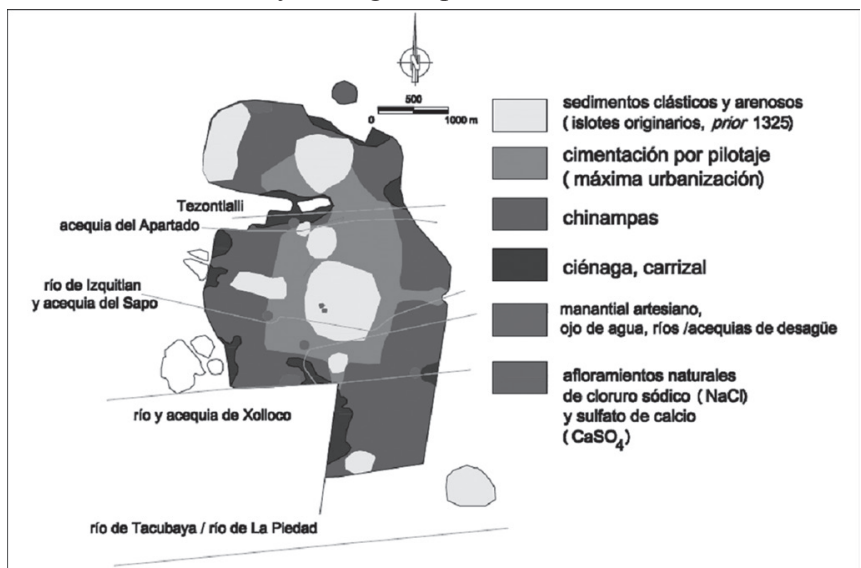

Fuente: diseño del autor en base a datos presentes en Sahagún, 2001 (1577); Calnek, 1972, 1976; González Aparicio, 1973; González Rul, 1988; Reyes García, et al. (eds.), 1996; Filsinger, 2005; Sánchez Vázquez, et al., 2007; Torre Villalpando, 2010.

\footnotetext{
$\overline{{ }^{10} \text { Calnek, 1972, p. 112; 1976, p. } 299}$ (Fig. 16).

${ }^{11}$ Ibid., 1974, pp. 48 y 53.

12 Ibid., 1972, pp. 112-114; "At the extreme limits of this area, the mirror image pattern was entirely abandoned, and each residencial platform was enclosed on 3 or even 4 sides by chinampas. Individual sites ranges up to 4000 or $5000 \mathrm{~m}^{2}$ in extent, well within the size range required to support a single nuclear family or slightly larger group [...]". Esta zona liminar del cuadrante sureste de Tenochtitlan se corresponde, dentro del moderno parcelario de México D. F., con el área comprendida entre la Avenida del Taller y el Eje 3 Sur Calzada de Chabacano de la delegación Cuauhtémoc.
}

${ }^{13}$ Archivo General de la Nación de México (AGN)-Tierras, vol. 20, 2a parte, exp. 4, f. 6r; AGN-Tierras, vol. 37 , exp. 2, ff. 77v-94v, f. 86r; Calnek, 1972, p. 114. En el vecindario rural de Huehuetla-Atlixocan-Tepetlatzinco existían, a mediados del siglo XVI, tenencias poseídas por miembros de la antigua aristocracia de Tenochtitlan que alcanzaban las 160 brazas de largo por 10 de ancho, es decir, unos $10.000 \mathrm{~m}^{2}$. Asimismo, en la zona campestre de Xochimilco fue habitual que los lotes domésticos chinamperos basculasen entre los $5.000 \mathrm{y}$ $10.000 \mathrm{~m}^{2}$, extensiones que se corresponden, en buena medida, a las observaciones que efectuó William T. Sanders $(1962,88)$ en parcelas familiares de localidades rurales del norte de la península de Yucatán.

${ }^{14}$ Cortés, 2000 (1520), Segunda Carta-Relación, p. 143; Mapa de Uppsala, c. 1550; Martos y Pulido, 1989, p. 87; Sánchez Vázquez, et al., 2007, pp. 156, 162, 168, 172 y 181 
De pueblos a barrios: reconfiguraciones espaciales y administrativas en la frontera...

Por otra parte, el marco de análisis político en las sociedades nahuas prehispánicas se centra en el altepetl $^{15}$. Se trata de una institución sociopolítica que, con anterioridad a la década de 1990, no había sido objeto de excesivo interés entre los investigadores. James Lockhart sostiene que su nombre deriva de la contracción de yn atl yn tepetl, difrasismo en lengua náhuatl que se puede traducir por el agua, la montaña ${ }^{16}$. Los vocabularios del religioso franciscano Alonso de Molina -elaborados, cabe recordar, en 1555 y 1571 - traducen altepetl por pueblo de todos juntamente, pueblo o rey ${ }^{17}$, hecho que vincula su naturaleza ontológica con el gobernante (tlahtoani) y su soberanía personal (tlahtohcayotl).

Sin embargo, se ha postulado también la identificación del altepetl centro-mexicano con los conceptos de ciudad-Estado o de Estado local étnico ${ }^{18}$, desatendiendo de forma clara el sistema de valores de los antiguos nahuas ${ }^{19}$. En efecto: estas categorías adolecerían de eurocentrismo y serían proyecciones contemporáneas hacia instituciones indígenas prehispánicas que no parecen haber primado la ciudad sobre el campo, o tampoco el papel de una única etnia -o nación- en los procesos de integración política. En el precitado diccionario de Molina del año 1571 no se registran entradas específicas que aludan al campo o al ámbito rural como entidades disociadas de la propia ciudad. Las aldeas rurales y la comarca reciben los sugestivos nombres de altepemaitl -es decir, mano del altepetl-y altepenahuac -cercano al altepetl-. Asimismo, la cabecera urbana es reconocida alegóricamente como altepeyolloco -en el corazón del altepet $^{20}$-, altepenanyotl -matriz o útero del altepetl-o totecuacan lugar donde se yergue nuestro señor- ${ }^{21}$.

En consecuencia, el altepetl fue conceptualizado y vivido como un ente orgánico o cuerpo, cuya anatomía se hallaba integrada por diferentes miembros interconectados y dependientes entre sí. Se puede apreciar, pues, que no existe una distinción conceptual tajante entre el campo y la ciudad en la mentalidad nahua ${ }^{22}$. El altepetl englobaba concepciones binarias que implicaban una fuerte carga de interdependencia y de complementariedad entre ambos ámbitos espaciales. Resulta más adecuado hablar de él en términos de corporación, pues los gobernantes (tlahtoqueh), señores (tetecuhtin)

\footnotetext{
${ }^{15}$ El plural es altepemeh (cfr. Chimalpahin, 1997 [c. 1620], p. 18).

${ }^{16}$ Lockhart, 1992, p. 14.

${ }^{17}$ Molina, 1555, f. 204r; 1571, f. 4r.

${ }^{18}$ Smith, 2000, pp. 581 y ss.; 2003a, p. 148; 2003b, pp. 35-39; Schroeder, 1991, p. 119; Lockhart, 1992, p. 607.

${ }^{19}$ No obstante, James Lockhart (1993, pp. 22-23) acabó admitiendo que el concepto de ciudad-Estado no es adecuado, puesto que enfatiza lo urbano por encima de lo rural, así como que tampoco existen vocablos homotaxiales en inglés para traducirlo adecuadamente. Propone vagamente su identificación con el término reino.

${ }^{20}$ María Elena Bernal y Ángel Julián García (2006, p. 61) defienden la intrínseca relación que guardaba este vocablo con la casa o pirámide del dios patrono (teocalli).

${ }^{21}$ Molina, 1571, ff. 4r, 150r.

${ }^{22}$ Hirth, 2009, p. 281.
} 
y principales (pipiltin) indios fueron quienes articularon y dotaron de movilidad a este cuerpo sociopolítico, integrado por sub-unidades administrativas menores o barrios, denominados calpolli y tlaxilacalli ${ }^{23}$.

En este punto cabe resaltar que las cabeceras de los altepemeh centro-mexicanos -y, ciertamente, Tenochtitlan no fue una excepción- ejercían control jurisdiccional sobre una serie de dependencias campestres. El vocabulario de Molina de 1571 las reconoce bajo la denominación de altepemaitl o altepetlianca ${ }^{24}$, y estas siempre son referidas en las narrativas históricas y administrativas del siglo XVI con los nombres castellanos de estancia, pueblo o sujeto $^{25}$.

Por su carácter pionero, merecen ser mencionadas las pertinentes observaciones que Charles Gibson realizó en relación a la distribución espacial de sujetos, centrándose en el caso de los altepemeh de Teotihuacan, Tepexpan y Acolman. El investigador concluyó que el mapa de estancias rurales de cada una de estas cabeceras era enmarañado, que podían no guardar contigüidad espacial con sus respectivos centros rectores y que los tres señoríos estaban entremezclados o entreverados, siendo imposible el establecimiento de fronteras precisas entre ellos ${ }^{26}$. El caso descrito para estos tres altepemeh es aplicable a otras amplias zonas del México Central, donde los núcleos rectores controlaban una pléyade de sujetos dislocados y repartidos selectivamente por un territorio multiétnico de elevada complejidad ecológica ${ }^{27}$. La relación de dominio a la cual un sujeto se encontraba sometido en la época prehispánica era compleja, y hasta podía satisfacer a múltiples centros rectores. Tal es así que existía una intrincada jerarquía de cabeceras y sujetos que conectaban a la más pequeña aldea con la gran México-Tenochtitlan ${ }^{28}$.

De este modo, tenemos conocimiento de la multi-dependencia de Cuauhtitlan hacia Tlacopan, Tenochtitlan, Tlatelolco, Colhuacan, Iztapalapa, Mexicaltzinco, Azcapotzalco o Texcoco ${ }^{29}$, así como de la del señorío de Molango en la Sierra Alta hacia Metztitlán, Huejutla de Reyes -o Huexotlan-, Tenochtitlan, Texcoco y Tlacopan ${ }^{30}$. Se disponía de un amplio repertorio de formas de reconocimiento de esta relación de sometimiento, que englobaba la donación obligatoria de tasas y tributos, servicios en trabajo, prestaciones militares, donación institucionalizada de presentes y de regalos

\footnotetext{
${ }^{23}$ Calnek, 1974, p. 26; 1976, pp. 296-297; 2003; Kellogg, 2005 [1995], p. 567; Reyes García, 1996, pp. 56-68; Alcántara, 2004, pp. 87 y ss. Sus plurales son calpoltin y tlaxilacaltin.

${ }^{24}$ Molina, 1571, f. 4r; "Altepetlianca: subjeto o comarca de ciudad o pueblo, o aldea de ciudad". De ahora en adelante, y siempre en este contexto, se utilizará el nombre de sujeto en cursiva (sujeto), con el fin de evitar confusiones semánticas con palabras homónimas.

${ }^{25}$ Cfr. Carrasco, 1996, p. 33.

${ }^{26}$ Gibson, 1986 (1964), pp. 50 y 51.

${ }^{27}$ Martínez, 1984; Smith, 2003b, p. 59; Hirth, 2009, p. 275; Rovira Morgado, 2010b, pp. 532-534.

${ }^{28}$ Hassig, 1985, pp. 103-110.

${ }^{29}$ Gibson, 1986 (1964).

${ }^{30}$ Rovira Morgado, 2010b, pp. 532-538.
} 
De pueblos a barrios: reconfiguraciones espaciales y administrativas en la frontera...

o trato preferencial para mercadear ${ }^{31}$. Estas relaciones de poder eran operativas en todos los niveles de la jerarquía política y administrativa y se hallaban cimentadas por el principio de dominación o fidelidad señorial, y no por el de territorialidad ${ }^{32}$. Arij Ouweneel y Rik Hoekstra defienden que este escenario o arena política amerindia recuerda al llamado Personenverbandstaat, sistema estatal feudo-vasallático basado en la conspicua relación patrón-cliente, característica del Bajo Medioevo en los principados del Sacro Imperio Romano-Germánico ${ }^{33}$.

En consecuencia, las fronteras de los altepemeh prehispánicos fueron más bien límites muy volubles de clientelas señoriales. Unas fronteras en las que -siguiendo las conocidas tesis de Armand Frémont en torno al space vécu en las sociedades tradicionales del mundo pre-industrial- ${ }^{34}$ las espacialidades serían constructos cognitivos por los que la comunidad reconocería la existencia de una memoria transgeneracional que las aprehendía, las construía, las negociaba y las transformaba de forma constante y recurrente.

En el caso de Tenochtitlan, la mayoría de estas fronteras tentaculares o dendríticas en las que sus sujetos se hallaban, se encontraban ampliamente distribuidas por la Cuenca de México $^{35}$. Un gran número de estas dependencias campestres aparecen enlistadas, en varios relatos históricos de tradición india de los siglos XVI y XVII, como lugares de parada y de reposo temporal de los mexicas durante su largo peregrinar desde la mítica Aztlan ${ }^{36}$. No obstante, estos datos muestran una serie de contradicciones con respecto a la información que aparece en fuentes nativas independientes o en litigios virreinales por la posesión de tierras, pues en estos se declara que el control sobre dichos sujetos era el resultado del expansionismo militar mexica del siglo $\mathrm{XV}^{37}$.

En consecuencia, estas estancias no constituirían elementos íntimamente relacionados con la etnogénesis de los mexica-tenochcas, sino más bien componentes consecutivos de su altepetl, cuyo auge arrancó tras la victoria sobre el centro rector de Azcapotzalco en $1430^{38}$. Es más: resulta altamente probable que los historiadores nativos del siglo XVI mostrasen particular interés por retratar dichas estancias como parte constitutiva o etnogenética de Tenochtitlan con el fin de reclamar la titularidad de estas tras la Conquista. Ciertamente: desde 1521-1522, el tejido administrativo de la mayoría de

\footnotetext{
${ }^{31}$ Hicks, 1991; Kobayashi, 1993; Berdan, et al. [eds.], 1996; Carrasco, 1996.

${ }^{32}$ Smith, 2003c, p. 59.

${ }^{33}$ Ouweneel y Hoekstra, 1998, pp. 6 y 7.

${ }^{34}$ Cfr. Frémont, 1970.

${ }^{35}$ Gibson, 1986 (1964), pp. 50 y 52; Lira, 1983; Carrasco, 1996, pp. 148-149, 172-175.

${ }^{36}$ Historia de los mexicanos por sus pinturas, 1988 (c. 1535), cap. XI, XVIII, XIX; Códice Aubin, 1576; Tezozomoc, 2001 (1598), cap. III, p. 61; 1998 (1598-1609), pp. 45 y ss., entre otros.

${ }^{37}$ Códice Cozcatzin, c. 1572 (?), f. 10r; Archivo General de Indias (AGI)-Justicia, leg. 159, n . 5, citado por

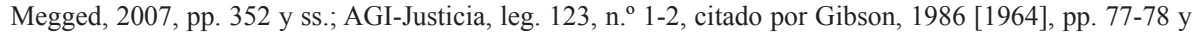
Hicks 2005, pp. 196 y ss.

${ }^{38}$ Cfr. Santamarina, 2006; Battcock, 2011; Castañeda de la Paz, 2013.
} 
los señoríos indios de la Cuenca de México se deshilvanó como consecuencia de las redistribuciones y de los repartos de tierras que el conquistador Hernán Cortés efectuó tempranamente ${ }^{39}$. Como veremos en breve, ello pudo provocar que los señores y los principales de Tenochtitlan solicitasen, en 1532 o en 1574, ante la Real Audiencia de la Nueva España, el Consejo de Indias o la misma Corona, la restitución de estos sujetos naturales dependientes de la ciudad ${ }^{40}$. Lo cierto es que Tenochtitlan aún disfrutaría del control sobre algunas estancias a finales del Virreinato ${ }^{41}$, bien que ese gozo fue parejo a la pérdida irremisible de otras muchas.

\section{La zona de Iztacalco, Mixiuhcan, Zoquipan y Toltenco en las fuentes documentales tempranas}

El límite y la frontera natural, por el sur, de la antigua isla de México-Tenochtitlan fue una difusa zona -llena de ciénagas, de lodazales y de cuerpos pantanosos que afloraban en medio de numerosos juncales y espadañas- en la que existían varios islotes dedicados a la agricultura chinampera, a la pesca, a la caza de fauna acuática o a la extracción salinera. Adelantábamos en el resumen y en la introducción que los sitios más importantes que las fuentes documentales del siglo XVI consignan para esta área conurbana inmediata son Toltenco, Zoquipan, Mixiuhcan y, varios quilómetros más hacia el sur, también Iztacalco.

Sin embargo, pocas son las informaciones y noticias conocidas, y anteriores a la década de 1550, que permiten confirmar que estos centros fuesen propiamente barrios constitutivos -o tlaxilacaltin- de Tenochitlan. La evidencia documental disponible respaldaría, por el contrario, que eran en origen altepetlianca, es decir, pueblos, estancias o sujetos subordinados a la capital de los mexicas. Como tendremos ocasión de comentar, su transformación jurídica habría empezado a acontecer en los años de 1550. Cabe señalar que de los catálogos vecinales sobre la ciudad prehispánica que Alfonso Caso, Luis González Aparicio o Edward E. Calnek publicaron, los tres primeros (Toltenco, Zoquipan, Mixiuhcan) se registran como barrios urbanos ${ }^{42}$. Es importante advertir no obstante que estos investigadores utilizaron, para tal efecto, la información contenida en una cartografía urbana - del año 1789- elaborada por el padre José Antonio Alzate y Ramírez. Ciertamente: en el plano Tenochtitlan Corte de los Emperadores Mexicanos, se señala que dichos barrios urbanos y también otros espacios adicionales, estaban dentro de la parcialidad mexicana de San Pablo ${ }^{43}$. El clérigo Alzate justificaba tal empresa con estas palabras:

\footnotetext{
${ }^{39}$ Ramírez de Fuenleal, 1870 (1532), p. 236; Motolinía, 2012 [1542]. Frederick Hicks (1992, p. 8) opina que Cortés obró de este modo para racionalizar o territorializar los dominios de los diferentes señoríos indios de la Cuenca de México, obstaculizando el clásico intercambio y entreveramiento de tenencias y estancias y facilitando el terreno a la política de reparto de lotes encomendados a los conquistadores.

${ }^{40}$ Ternaux-Compans, 2011 (1838), pp. 261-269; AGI-México, leg. 282, citado por Carrasco, 1996, p. 148.

${ }^{41}$ Cfr. Lira, 1983.

${ }^{42}$ Cfr. Caso, 1956; González Aparicio, 1973; Calnek, 2003.

${ }^{43}$ Biblioteca Nacional de Francia-Fonds Mexicain, Ms. 150. Como veremos seguidamente, en la época novohispana la población indígena de la Ciudad de México se organizó en cuatro barrios grandes, cabeceras o parcialidades: San Juan, San Pablo, Santa María La Redonda y San Sebastián.
} 
De pueblos a barrios: reconfiguraciones espaciales y administrativas en la frontera...

Para dar una idea de la población del Antiguo México, me ha parecido muy útil combinar ambos planos -este con el del alférez Ildefonso Iniesta Bejarano-, esto es, los nombres antiguos con los Modernos para que en los tiempos venideros se sepan los Barrios y sus estribaciones, respecto á que se van exterminando con prontitud las denominaciones Mexicanas, dicha combinación servirá para la inteligencia de mucha parte de la historia ${ }^{44}$.

Dicho plano formó parte del proyecto cartográfico e historiográfico que acompañaría a la secularización tardo-virreinal de parroquias indias y españolas, realizada a instancias del arzobispo Francisco A. Lorenzana en la década de 1770. De esta manera, puede considerarse que Alzate actuó imbuido por el universo referencial del Arzobispado de México ${ }^{45}$, el cual también estaba interesado en potenciar nuevos centros curales en el seno de los propios vecindarios indígenas. Por mucho que el mapa urbano de Alzate destaque por su minuciosidad, es obvio que respondió a objetivos muy concretos de la época en la que fue elaborado, y que las fuentes de información que utilizó el religioso se caracterizan por un elevado grado de opacidad y, tal vez, tendenciosidad.

Lo cierto es que datos contenidos en fuentes de información mucho más tempranas a esta, los referenciados a finales del siglo XVIII no refrendarían la opinión de Alzate de que esos barrios meridionales que se documentan como tales en las postrimerías de la era virreinal, fuesen originariamente poblaciones del Antiguo México. Todos los centros que, en la época prehispánica, rodeaban la frontera sur de la isla -situada entre las actuales Avenida del Taller y Calzada de Chabacano, en la delegación Cuauhtémoc de México D.F- parecen haber sido transferidos a Tenochtitlan tras su victoria frente a los vecinos altepemeh de Azcapotzalco y de Coyoacán. Varias son las noticias que respaldan este hecho. Por una parte, el cronista indígena Hernando de Alvarado Tezozomoc comenta, en su Crónica mexicana del año 1598, que uno de los enclaves fronterizos importantes en los que tuvo lugar, hacia 1428, el enfrentamiento entre los tenochcas y estos dos centros de poder fue el de Xoconochnopalyacac ${ }^{46}$. El autor Domingo Francisco de San Antón Muñón Chimalpahin comenta asimismo, que Xoconochnopalyacac se localizaba en la proximidad de una acequia que corría desde San Antonio Abad Oztocaltitlan, en el tlaxilacalli de Xolloco Acatla en San Pablo, en dirección a las inmediaciones del tlaxilacalli de Amanalco, ya en la parcialidad de San Juan ${ }^{47}$. Finalmente, si confrontamos estas noticias con la información gráfica que aparece en el denominado Mapa de Uppsala (c. 1550), observamos la presencia de un pequeño canal que, situado a las espaldas de la iglesia de San Antonio Abad, desembocaría en la ciénaga que se disponía hacia los barrios de la cabecera de San Juan $^{48}$. Dicha corriente de agua fue el antecedente de la actual Avenida del Taller. Es más: el Mapa de Uppsala sitúa, muy cerca de allí, una cruz cristiana, erigida justo en la entrada de la ciudad virreinal. Según la opinión del fraile dominico Diego Durán, en ese punto había existido, en tiempos de la gentilidad, el

\footnotetext{
${ }^{44}$ Ibid., f. $1 \mathrm{r}$.

${ }^{45}$ Moreno de los Arcos, 1982; Sánchez Santiró, 2004, pp. 80-81.

${ }^{46}$ Tezozomoc, 2012 (c. 1598), cap. X, p. 40.

${ }^{47}$ Chimalpahin, 2006 (c. 1620), pp. 84-85.

${ }^{48}$ Mapa de Uppsala, (c. 1550).
} 
[...] lugar donde estaba el templo de la diosa-Toci-, que era casi fuera de la ciudad, donde agora está la primera cruz, como salimos de México en la calçada, y allí, frontero del mismo cruçillo que allí tenían y de unos palos muy altos y gruesos, encima de los cuales estava armado un tablado muy bien hecho, donde tenían la estatua de la diosa puesta $[\ldots]^{49}$.

Este adoratorio dedicado a la diosa Toci -o Tocititlan- en el acceso meridional de la antigua Tenochtitlan suponía un claro espacio liminar que señalaba una mojonera esencial del territorio mexicano; pues se consideraba que era un importante umbral o un punto de paso iniciático en el que tenían que acontecer rituales de purificación mediante combates simulados, escaramuzas militares fingidas y sacrificios con los vecinos enemigos ${ }^{50}$. Consecuentemente, los espacios externos a este Tocititlan que quedaban por el sur -es decir, aquellos ubicados más allá donde hoy en día la Avenida del Taller y la Calzada de Chabacano se yerguen- eran lugares conquistados. Y ello concuerda con lo que se registra, en ciertas fuentes, en relación al estatus de pueblos sujetos y terrazgueros que tenían todos los núcleos poblacionales que se encontraban entre esta zona: Iztacalco, Mexicaltzinco y Coyoacán.

En efecto: en el Códice Cozcatzin, se relata que, tras la victoria de Tenochtitlan frente a los tepanecas de Azcapotzalco, el tlahtoani o gobernante Itzcoatl "[...] rrepartió [...] tierras en 1439 a los que conquistaron desta ciudad de México -enYtzaltytenco y en Atlyxocan [...]"51. Por su parte, Francisco López de Gómara asevera que todas las localidades que se hallaban desde Mexicaltzinco a la Ciudad de México estaban especializadas en la explotación salinera y que esta "[...] era gran renta para Moctezuma [...]"52. A este último resulta interesante mencionar que, en fechas avanzadas del siglo XVI, algunos sujetos naturales de Iztacalco -como eran los de Tetepilco, Huehuetla o Tepetlatzinco-Atlixocan- ${ }^{53}$, evidenciaban todavía la presencia de renteros (mayequeh ó tlalmaitin, en lengua náhuatl), ligados por lazos de servidumbre a la nobleza de Tenochtitlan mediante el pago de unos terrazgos que solían incluir panes de sal, fauna acuática y productos agrícolas ${ }^{54}$. Este fenómeno estaría relacionado con la condición administrativa prehispánica que Iztacalco había guardado con respecto a México-Tenochtitlan, pues era un pueblo o una estancia sujeta al calpixcazgo -o una red tributaria- de Citlaltepec ${ }^{55}$ (Figura 3.).

\footnotetext{
${ }^{49}$ Durán, 1897 (1581), cap. LXII, pp. 484-485. Cursiva del autor.

${ }^{50}$ Mazzetto, 2014; Mazzetto y Rovira Morgado, 2014, pp. 110-114.

${ }^{51}$ Códice Cozcatzin, c. 1572 (?), f. 10r. Cursiva del autor.

${ }^{52}$ López de Gómara, 2003 (1552), p. 168. Cursiva del autor.

${ }^{53}$ Cfr. Códice Osuna, 1565, f. 11r. El conjunto de estancias dependientes del pueblo de Iztacalco eran las siguientes: Acaquilpan, Atzahuacan, Nexticpac, Acolco, Zacatlalmanco, Tetepilco, Zacahuitzco, Tepetla[tzinco], Huehuetla y Cha[...] (Ibid.).

${ }^{54}$ AGN-Tierras, vol. 24, exp. 3, ff. 111r-111v; AGN-Tierras, vol. 37, exp. 2, ff. 77v-94v, f. 86v; AGNTierras, vol. 46, exp. 4, f. 2r / 387r; AGN-Tierras, vol. 20, $2^{\mathrm{a}}$ parte, exp. 4, citado por Reyes García, et al. (paleografía y edición), 1996, p. 99.

${ }^{55}$ Códice Mendocino, 1542, f. 17v. Junto a Iztacalco, el resto de pueblos dependientes del calpixcazgo de Citlaltepec estaba integrado por Tzompanco, Xaltocan, Acalhuacan, Coatitlan, Huixachtitlan (IxhuatepecTola), Acolnahuac, Puputlan y Chalco Atenco (Ibid.).
} 
De pueblos a barrios: reconfiguraciones espaciales y administrativas en la frontera...

Figura 3. Principales altepemeh, estancias y sitios ceremoniales al sur de la isla de México durante el último momento prehispánico. (Se señala con líneas punteadas la acequia discutida).

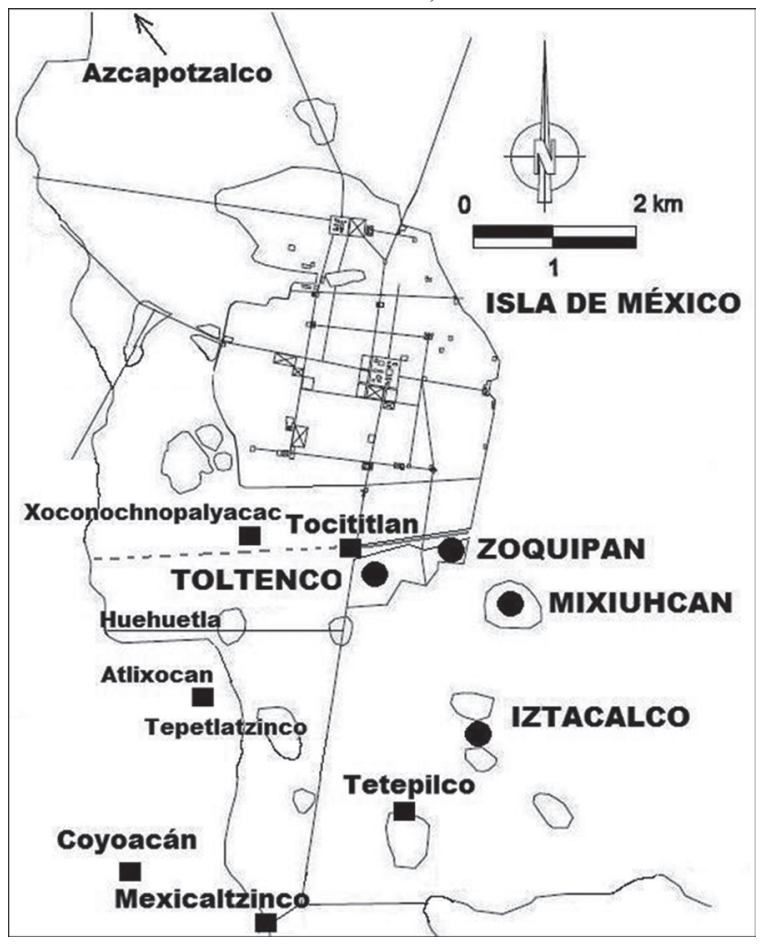

Fuente: diseño del autor.

Todo este entramado de relaciones de sujeción clientelar, que había hecho posible el drenaje del tributo en servicios y en especie de las aldeas más pequeñas a la gran capital prehispánica, se sustentaba, en última instancia, por el hecho de que este calpixcazgo de Citlaltepec se había encargado de ofrecer movilización y protección militar a los mexicas en la Cuenca de México. En este sentido, na parte poco despreciable de sus beneficiarios eran experimentados guerreros mexicas que, habiendo destacado en hazañas militares, habían recibido un ennoblecimiento meritorio, ascendiendo, desde entonces, a los rangos y a los estatus de tequihuaqueh y quauhpipiltin. Estos principales, que fungían como una influyente nobleza secundaria de servicio, fueron gratificados con concesiones en forma de tenencias agrarias en las localidades dependientes precisamente de Citlaltepec ${ }^{56}$.

Además, es importante señalar que muchos de estos guerreros ennoblecidos evidenciaron una vinculación residencial en Tenochtitlan con los tlaxilacaltin y el calpolli prehispánicos de Huitznahuac, espacios que, ya en el siglo XVI, se terminaron identificando con la parcialidad novohispana de San Pablo de México ${ }^{57}$.

\footnotetext{
${ }^{56}$ Van Zantwijk, 1967, pp. 150 y ss.; Kobayashi, 1993; Carrasco, 1996, pp. 166-167.

${ }^{57}$ Rovira Morgado, 2010b; 2013, pp. 164, 177, 179-180.
} 
En resumen: desde 1430 en adelante, los núcleos poblacionales ubicados en el sector periférico meridional de la isla de México se fueron convirtiendo en estancias sujetas a Tenochtitlan. Su relación de subordinación con respecto a los gobernantes, señores y principales de la ciudad-que recibieron tierras con motivo del expansionismo militar mexica- se basó en el pago recurrente de tributos, rentas y terrazgos de sal, pesca, caza y productos de cultivo chinampero, en los servicios personales y las extracciones de fuerza de trabajo y en la obligación de participar en ciertos rituales que implicaban actos de violencia institucionalizada.

Tras la llegada de Hernán Cortés en 1519 y del proceso de conquista de 1520-1521, Toltenco, Zoquipan, Mixiuhcan e Iztacalco mantendrían parcialmente su condición de pueblos o sujetos dependientes de la sojuzgada México-Tenochtitlan, situación que se habría perpetuado hasta mediados de la década de 1550 . Un aspecto que parece refrendar esta profunda subordinación -que las estancias ubicadas alrededor de la calzada de Iztapalapa, de Iztacalco y del camino de Tacubaya a Coyoacán continuaban mostrando aún hacia las autoridades de Tenochtitlan en la década de 1520 - es la transacción de predios que los fieles gobernadores indígenas instalados por Hernán Cortés acordaron efectuar muy cerca de allí con el cabildo español de la Ciudad de México, instituido en el año de 1524. En efecto: don Andrés de Tapia Motelchiuhtzin -antiguo quauhpilli y líder nativo promovido por el conquistador español en 1525- tuvo que estar involucrado en el repartimiento de las treinta y una huertas a vecinos castellanos que, el 14 de agosto de 1528, las autoridades concejiles hicieron en las cercanías de la calzada, partiendo del extremo sur de la isla de México para conducirse hacia las localidades Tacubaya y Coyoacán. Estas fronteras ejidales del municipio español fueron consolidadas un año más tarde ante ciertos señores de Tenochtitlan y Tlatelolco ${ }^{58}$. Procediendo de dicha forma, el solícito Motelchiuhtzin estaría solo cambiando la titularidad de estos sujetos a los nuevos señores castellanos beneficiados. No resulta extraño, pues, que, a los pocos años, la alta nobleza de sangre de Tenochtitlan recriminase veladamente las actuaciones del advenedizo Motelchiuhtzin.

En la carta que, en 1532, varios miembros destacados de las parentelas de los antiguos gobernantes prehispánicos de Tenochtitlan hicieron llegar a la Corona, se atestiguaba que las localidades de Nihalco [sic por Iztacalco] y Coyoacán, entre otras, eran posesiones naturales de Tenochtitlan, y que las autoridades de la ciudad española habían decretado que en sus terrenos no se cultivasen y que más bien fuesen destinados a las pasturas y a los ejidos de los vecinos peninsulares ${ }^{59}$. No sabemos hasta qué punto los alegatos sobre estos pueblos, estancias y sujetos sureños que realizaban los señores y principales de Tenochtitlan estaban influyendo en los proyectos historiográficos indígenas que se estaban elaborando en esta década de 1530. Pero, en la Historia de los mexicanos por sus pinturas se comentaba significativamente, recordando los pasajes que rodearon la fundación de Tenochtitlan en la anterior época prehispánica, que

\footnotetext{
${ }^{58}$ Actas de Cabildo de la Ciudad de México (ACCM), 1889, Libro I, pp. 178-179; Libro II, p. 20.

${ }^{59}$ Ternaux-Compans, 2011 (1838), p. 266.
} 
De pueblos a barrios: reconfiguraciones espaciales y administrativas en la frontera...

[...] comenzamos a entrar en el término de Temustitlán, México, o a poblar, $y$ llegaron a Ixtacalco, que es estancia junto á México, e de ay fueron a Mixiuhcan do $<$ nde $>$ parió una mujer y le pusieron este nombre que quiere decir el par [i] dero, y de ay asentaron en el barrio que se dice Temascaltitlán, que quiere decir barrio del baño, y agora $<\mathrm{es}>$ la colación y barrio de San Pedro é San Pablo. ${ }^{60}$

Pese a que dicha fuente no mencione a las contiguas estancias de Toltenco y Zoquipan por no haber participado en los eventos inaugurales que rodearon a la etnogénesis de los tenochcas, sí se alude explícitamente a Iztacalco y a Mixiuhcan como pueblos y sujetos, en clara contraposición a Temazcaltitlan y a San Pablo, espacios urbanos que son considerados como barrios. Dicha distinción -importante en este momento del siglo XVI, en el que predominaba aún una legitimidad señorial en la reclamación de las estancias comarcanas adquiridas por el derecho justo que la guerra gentil había aportado- fue mutando a medida que, del tlahtohcayotl superviviente de la Conquista, se entró en el cabildo y en la república de naturales, reelaborándose, entonces, las taxonomías administrativas.

\section{El proceso de transformación: los acontecimientos de los años 1555 y 1556}

Hasta el momento, hemos tenido la oportunidad de plantear el carácter de pueblos, sujetos o estancias que tendrían los lugares situados en la raya meridional de la isla de Tenochtitlan tanto en la época prehispánica tardía como en las primeras décadas que siguieron a la Conquista. La transformación de Toltenco, Zoquipan, Mixiuhcan e Iztacalco en barrios adscritos a una cabecera doctrinal y política muy concreta -la de San Pablo de México- estuvo relacionada con la génesis y el desarrollo temprano del cabildo indígena en la ciudad, aunque, decididamente, con ciertas circunstancias que acontecieron en los años que rodearon el ecuador del siglo XVI. Empecemos comentando que, por bien que los gobernadores legítimos en Tenochtitlan empezaron a ser instalados en las postrimerías de la década de 1530, no fue sino hasta el año de 1549 que se instituyeron los primeros alcaldes electos ${ }^{61}$. Entre 1549 y 1554, el personal concejil nativo se incrementó con mayordomos de comunidad y alguaciles ${ }^{62}$. Desde finales de 1554 se documentan los primeros regidores. Así pues, a caballo en las décadas de 1540 y de 1550 , los señores indígenas tuvieron que entrar en cabildo. El proceso no fue fácil, pues el gobernador de aquel momento, don Diego Tehuetzquititzin, fue objeto de una serie de juicios de residencia realizados por Mateo Juárez, de Tepeaca y Francisco Vásquez, de Cholula (1549-1550/1551); y también por Esteban de Guzmán, de Xochimilco (1554-1557) ${ }^{63}$.

Inciso especial merece el último de estos tres funcionarios indígenas. En efecto: el juez de residencia Esteban de Guzmán procedía de una localidad, Xochimilco, en la que, en el año 1552, se había celebrado un importante capítulo de la provincia franciscana

\footnotetext{
${ }^{60}$ Historia de los mexicanos por sus pinturas, 1988 (c. 1535), cap. XIX, p. 77. Cursiva del autor.

${ }^{61}$ Códice Aubin, 1576, f. 47v.

${ }^{62}$ AGN-Civil, vol. 644, exp.1, ff. 95r-97r.

${ }^{63}$ Ibid.
} 
novohispana del Santo Evangelio en el convento local de San Bernardino de Siena ${ }^{64}$. En menos de doce meses, De Guzmán fue promocionado al cargo de gobernador en Xochimilco, y ya en 1553 se redactaron unas ordenanzas municipales con clara influencia seráfica ${ }^{65}$. Sería por ello que, el 15 de junio de 1554, el virrey Luis de Velasco le comisionase para el cargo de juez de residencia en Tenochtitlan, por ser "[...] persona de confianza [...]”, y para que pudiese también esclarecer y “[ [...] averiguar los rrobos delitos eçesos que ubieren abido en rrepublica <india $>$ desta çiudad de la parte de mexico [...]" y todo aquello que "[...] se obiessen llevado fuera de la tasaçion $<$ de la caja de la comunidad $>[\ldots]^{\prime \prime 66}$. En los seis meses que transcurrieron desde la llegada de Esteban de Guzmán a la Navidad de 1554, la gobernación autónoma de los tenochcas dependió de un hilo. Pero los franciscanos defendieron hábilmente, ante el virrey Velasco y ante las altas esferas de la Real Audiencia, el derecho natural a que existiese una república indígena en la capital novohispana. En la carta que el propio Esteban de Guzmán y otros funcionarios, señores y principales nahuas, enviaron al príncipe Felipe de Habsburgo se comentó al respecto que:

[...] Otra cosa es nuestro pesar, que ahora recientemente nos agobia. Hoy eso ante ti lo hacemos público a voces, a ti, nuestro amado príncipe, porque en el reciente año de 1554 querían quitarnos el mando, la administración, lo que nos dejaron nuestros padres, nuestros abuelos, que fuera entregado a los españoles. Esto, señor, ya hubiera ocurrido con nosotros, si no nos lo protegieran nuestros reverenciados padres de San Francisco, porque así cumplieron su obligación para con todos nosotros [...]. Han sido constituidos dos alcaldes mayores, uno aquí en México se ocupa, y el otro en Tlatelolco. Ellos se encargan de la gobernación y del regimiento y de la justicia. Y cuando atienden, ejercen autoridad, luego lo decimos ante tu representante, don Luis de Velasco, vissorrey, $y$ también ante los padres de San Francisco que por nosotros hablaron $[\ldots]^{67}$.

Fue en estos primeros tiempos de la residencia de Esteban de Guzmán en los que las cuatro doctrinas de indios que, desde 1524 en adelante, los religiosos franciscanos venían administrando en México-Tenochtitlan -Santa María La Redonda, San Juan, San Pablo y San Sebastián - hasta adquirir plena personalidad jurídica, administrativa y política para que fuesen los distritos electorales que dispondrían de representatividad en el cabildo indígena. De ese modo, y desde enero de 1555, “[...] el gov.or y principales de la parte de mx.co començaron a tener horden y poliçia en la eleçion de gov.or alcaldes y rregidores y en la provyçion delas cosas de su rrepublica $[\ldots]^{\prime \prime 68}$. Durante buena parte de la década de 1550 y de la siguiente de 1560 , esta elección de los cargos y de los oficios públicos en la república de yndios de Tenochtitlan atendió a un sistema rotatorio y corporativo entre las cuatro parcialidades, por el cual durante un año eran escogidos dos alcaldes: uno por San Juan y otro por San Pablo que, en

\footnotetext{
${ }^{64}$ Anales de Tecamachalco, 1992 (c. 1590), p. 32; Mendieta, 2012 (1596), Libro IV, cap. XLII, p. 536; Nybo Rasmussen, 1992, p. 79-89.

${ }^{65}$ Cfr. Pérez Zevallos, 1984, pp. 445 y ss.

${ }^{66}$ AGN-Mercedes, vol. 4, exp. 118, f. 35v.

${ }^{67}$ AGI-México, Leg. 158, citado por León-Portilla (trad., paleog., y ed.), 2001, pp. 248, 249, 250 y 251. Cursiva del autor.

${ }^{68}$ AGN-Civil, vol. 644, exp.1, ff. 145r-172v, f. 145r.
} 
De pueblos a barrios: reconfiguraciones espaciales y administrativas en la frontera...

el siguiente, serían reemplazados por dos procedentes de Santa María La Redonda y San Sebastián ${ }^{69}$. Los múltiples barrios urbanos, o tlaxilacaltin, adscritos a cada una de estas doctrinas/parcialidades de la república de naturales tendrían que sufragar una cuarta parte de los gastos de la comunidad concejil ${ }^{70}$, del tributo en servicio personal colectivo -o coatequitl- pagado a la Corona ${ }^{71} \mathrm{y}$, de forma altamente significativa, también del sustento material de "[...] los ministros $<$ franciscanos $>$ que tienen cargo de su cristiandad $[\ldots]^{\text {"72 }}$.

Era evidente, pues, que las arcas públicas de la caja de la comunidad tenían que estar saneadas para satisfacer, en tiempo y en forma, todas estas obligaciones impositivas y fiscales. Por tanto, se requeriría un control estricto de todos los vecinos maceguales residentes en los tlaxilacaltin. Sin embargo, en estas décadas en las que florecían los cabildos y las repúblicas en los centros indígenas, el arzobispo Alonso de Montúfar alertaba, ya el día 15 de mayo de 1556, de los notables inconvenientes que existían en dicho proceso constitutivo, y asimismo aportaba noticias importantes acerca de cómo algunos pueblos, estancias y sujetos estaban implementando fuertes estrategias de centrifugación con respecto de sus antiguas cabeceras:

[...] señalaremos aquí cosas que su magestad [...] conviene las mande remediar, porque son grandes tiranías, robos y servidumbres y cautiverio en que están estos pobres naturales [...]. La primera es las comunidades que llaman en esta tierra, que son inventadas por los religiosos [...] es el caso que algunos santos religiosos de los primeros <que llegaron a la Nueva España> para que estos pobres indios tuviesen de qué sustentar los ministros de la Iglesia y para algunos beneficios públicos sin que se les echasen tributos, dieron una orden como en algunos pueblos donde ellos estaban hiciesen los indios de aquella comarca una sementera o caleras $[\ldots]$ criasen ganado $[\ldots]<0$ ó $>$ trujesen leña o yerba $[\ldots]$ y que el dinero que dellos se sacase su pusiese en una caja y casa [...] no solamente los pueblos donde los religiosos están hay las dichas cajas de comunidad, pero cada cabecera y muchos subjetos han hecho y cada día hacen semejantes cajas y casas donde hay muchos bienes [...] digo que los religiosos son señores de las dichas comunidades y cajas en sus districtos $[\ldots]^{73}$.

Si Montúfar temía que con el auge de las cajas y de las casas de comunidad en los pueblos indígenas se pudiese incrementar el número de religiosos mendicantes

\footnotetext{
${ }^{69}$ Gibson, 1953.

${ }^{70}$ Códice Indígena de 1564-1565. Benson Latin American Collection (BLAC)-Colección Genaro García, Ms. 42, ff. 23.

${ }^{71}$ Memorial de los gastos que han hecho el governador y principales en las obras públicas desde el principio del año 55 hasta el de 65. AGN-Civil, vol. 644, exp. 1, ff. 145r-173v. Aclaramos que, tras la conquista de 1521 , los tenochcas gozaban de un régimen de exención tributaria por el cual no pagaban moneda a la Corona. La única relación de sometimiento impositivo y fiscal se basaba en la participación obligatoria de los servicios laborales multivecinales de obra pública en la Ciudad de México, sede de un corregimiento y cabecera política de la Nueva España. Esta aportación indígena en trabajo colectivo se conmutó por el pago de tributo en moneda per capita a partir de 1564. Anales de Juan Bautista, 2001 (1582), pp. 185-187, 211-213, 231-233; Gibson, 1986 (1964), p. 393.

${ }^{72}$ Montúfar, 1958 (1562), p. 33.

${ }^{73}$ Epistolario de la Nueva España (ENE), vol. VIII, pp. 85-87. Cursiva del autor.
} 
que las administrarían, no menos cierto es que los gobernadores, los alcaldes y los regidores nativos sufrirían aún más por la replicación que, de estos mismos aparatos institucionales, podía derivarse a causa de la fragmentación e independencia de sus estancias y sujetos. Una vía idónea que se podría haber hallado al utilizar para inhibir la formación de nuevas y legítimas repúblicas de naturales en estos antiguos sitios comarcanos dependientes de las cabeceras indígenas tradicionales, sería la redefinición jurídica y administrativa de dichos espacios. Su condición de pueblos adscritos sería sometida a una conveniente obliteración en aras de conceptualizarlos como barrios, es decir, como unidades residenciales constitutivas del altepetl. Y, de ese modo, ya no se podrían considerar más como simples estancias adquiridas por derecho de guerra antes de 1519; es decir, como apéndices consecutivos y sometidos del altepetl.

A este último respecto, cierta documentación que se elaboró en los primeros momentos del citado juicio de residencia de Esteban de Guzmán, resulta sumamente esclarecedora. El llamado Cargo y descargo que los macehuales de los cuatro barrios de México hacen a don Diego ante el juez don Esteban. Año $1553^{74}$ aporta datos importantes para entender el proceso de transformación taxonómica de ciertas estancias y de sujetos conurbanos importantes -como Iztacalco- a barrios que iniciarían su adhesión a las cabeceras mexicanas más cercanas. Los primeros folios de esta importante fuente de archivo, en la que se recogen las primeras actuaciones judiciales de Esteban de Guzmán a las tropelías de Tehuetzquititzin en 1554, atañen a las acusaciones que los barrios de la cabecera política y doctrinal de San Pablo vertieron en contra de este gobernador indígena ${ }^{75}$. Incorporado este apartado como parte integral de los vecindarios demandantes de esta parcialidad, al final de dicho documento aparece:

Yztacalco barrio // piden q' de la pesca y caça le diero' tres $\mathrm{ps}^{\circ}$. y tres mil y mil dos c. cacaos // confiesa' como arriba // piden qu' abiendoles a ellos p.hibido el pescar $<$ Tehuetzquititzin $>$ dio liçencia a los de ytztapalapa $[\ldots]^{76}$.

Los primeros pasos hacia la plena integración de Iztacalco -en tanto ente jurídico con derechos y obligaciones, barrio tributario de la república de yndios de Tenochtitlan y visita vecinal de la doctrina de San Pablo, este último que era vicaría de la iglesia de San José de los Naturales en el convento de San Francisco de México- se estaban insinuando ya hacia 1554 y 1555 . Precisamente, en ese concluyente año de 1555, entre los meses de junio y noviembre, tuvo lugar la celebración del I Concilio Provincial Mexicano promovido por el comentado arzobispo Alonso de Montúfar. El prelado se quejaba de que "[...] las órdenes han mostrado no mucho contentamiento [...] y así han predicado en esta nuestra iglesia no con poco descontento desta cibdad sobre cosas tocantes al Santo Concilio [...]"77 . En este sínodo episcopal se llegaron a múltiples resoluciones, entre las cuales conviene e interesa destacar la de cercenar de

\footnotetext{
${ }^{74}$ BLAC-Colección Genaro García, Ms. 30, 10 ff.

${ }^{75}$ Ibid., ff. 1v-3r.

${ }^{76}$ Ibid., f. 3r. Cursiva del autor.

${ }^{77}$ ENE, vol. VIII, p. 37.
} 
De pueblos a barrios: reconfiguraciones espaciales y administrativas en la frontera...

raíz el predominio franciscano en ciertos pueblos y comunidades indígenas del Valle de México. Ciertamente: el prelado informaba, en la nueva carta que envió al Consejo de Indias el 15 de mayo del siguiente año de 1556, que

[...] aun aquí en México, donde habían de ser mejores xriptianos, los indios son los peores y la causa es porque, como son tan innumerables y solamente han sido doctrinados en San Francisco, a pedimiento de los otras religiones $<$ de dominicos y agustinos $>$ y con parescer de vuestro visorrey y del Santo Concilio donde se pidió, repartimos los indios a todas tres órdenes y de seis partes quedaron las cinco a Sant Francisco, hanlo sentido tanto los padres de Sant Francisco como si les quitaran sus propios vasallos $[\ldots]^{78}$.

Según la opinión de Edmundo O’Gorman y de Fidel de Jesús Chauvet, esa sexta parte de las fundaciones y de las visitas franciscanas que el arzobispo Montúfar logró secularizar entre 1555 y 1556, englobaría, entre otras, a las localidades de Huehuetoca, Coyotepec, Tehuiloyucan, Tizayuca, Tepeyac(ac), Coyoacán, Cuitlahuac $\mathrm{y}$, significativamente, Iztacalco ${ }^{79}$.

Así pues, ¿cómo estarían reaccionando las autoridades seráficas en MéxicoTenochtitlan frente a este reto arzobispal?, ¿establecerían algún tipo de alianza al respecto con el concejo nativo para que ambos afianzasen su dominio en los barrios de una república de naturales que la propia orden franciscana patrocinaba mediante dichas estrategias de agencia colectiva ${ }^{80}$ ? Conviene advertir que, mientras todo esto sucedía, aconteció la gran inundación de la Ciudad de México del año 1555. Los aguaceros y las trombas de agua empezaron de forma virulenta en el mes de septiembre y ocasionóla anegación de amplias superficies en la isla y en la propia urbe. Las autoridades hispanas reaccionaron de inmediato ante la previsión de que, con las lluvias que se iniciarían a partir de mayo del año siguiente, la situación podría empeorar drásticamente. Particulares, como fue el caso de Francisco Gudiel, apostaron por un proyecto de magna ingeniería hidráulica que consistía en el desagüe integral de los cuerpos lacustres que rodeaban a la ciudad. Desde el cabildo español se apoyó dicha propuesta entre octubre y diciembre ${ }^{81}$, al tiempo que la Real Audiencia y el virrey Velasco respaldaban la idea de que las obras se centraran únicamente en reparar un antiguo albarradón de origen prehispánico que resguardaba a la isla de México en

\footnotetext{
${ }^{78}$ ENE, vol. VIII, p. 73. Cursiva del autor.

${ }^{79}$ Chauvet, 1981, pp. 46-47 y 143; O’Gorman, 1986, pp. 39-40. Resulta sugerente observar también que muchas de estas visitas secularizadas coinciden con lugares indígenas vinculados con el antiguo calpixcazgo de Citlaltepec. La dinámica de traspasar su administración temporal y espiritual al clero secular parece que esgrimió un modelo de periferia-centro, puesto que, como veremos en breve, el cabezal tenochca de la red, San Pablo de México (el antiguo Huitznahuac), pasó a manos del Arzobispado entre 1556 y 1565.

${ }^{80}$ Seguimos las premisas teóricas de los sociólogos Alain Touraine (1981, 1995, 2000), Stephan Fuchs (2001) y Martin Hewson (2010, pp. 12 y 13) en torno a las tácticas de actuación y de transformación por parte de individuos/corporaciones dentro de la sociedad. Consideramos que, a los efectos que estamos analizando aquí, la Orden de San Francisco generó acción e identidad corporativa hacia la comunidad de naturales en la capital novohispana durante incidentes puntales altamente críticos, que, durante este período de 1549-1555/1556, pudieron haber hecho llegar a peligrar su sostenibilidad y autogobierno.

${ }^{81}$ O’Gorman, 1970
} 
su perímetro oriental. Finalmente, la "(re)construcción" de este muro, hecho de piedra y céspedes por la comunidad indígena, se inició a principios del mes de diciembre de 1555 , elaborándose una probanza sobre su consecución en $1556^{82}$. Mucho se ha escrito sobre el impacto ecológico que este acontecimiento tuvo, de las fricciones manifiestas que se produjeron entre el virrey y las autoridades del consistorio español en relación con el financiamiento de las obras, o hasta de la vinculación de ello con la génesis del fenómeno guadalupano. Aunque, según nuestro parecer, un aspecto escasamente investigado y mencionado es el de advertir en qué grado la "(re)construcción" de este "albarradón de las Atarazanas" habría podido influir en la comunidad de naturales, en la apropiación de nuevos terrenos para su república y, ante todo, en la reconfiguración de la topografía insular durante los años clave del juicio de residencia de Esteban de Guzmán. Una explicación que abriría una sugerente ventana al respecto la ofrece la declaración del principal Francisco Atlauhcatl, incorporada a la probanza de 1556:

\begin{abstract}
XVII. A las diez e siete preguntas < este informante > dixo que sabe y es publico e notorio, que la república desta çibdad de México, ansí la de los españoles como la de los yndios, se proveen de los mantenimientos neçesarios e materiales para hazer sus cassas e otros edificios por canoas por la laguna, y si la dicha laguna se desaguase de manera que no pudiesen andar las canoas, todos los naturales reçebirían muy gran detrimento por no se poder proveer de lo susodicho, y no podría dexar de despoblarse mucha parte desta dicha çiudad, e yrse los naturales della a otras partes, y ansí memso los españoles reçeberían gran daño a cavsa de que no podrían ser proveídos de los dichos mantenimientos e materiales $^{83}$.
\end{abstract}

En paralelo a la defensa de esta república de naturales -recordemos, bajo el juicio de residencia de De Guzmán- que tenía que ser tan legítima como la española, Francisco Atlauhcatl nos hace entender que el proyecto de Gudiel no era conveniente para el mantenimiento del frágil statu quo que, desde 1524, los indígenas y los peninsulares venían estableciendo en la urbe. Desde entonces, una cuestión espinosa había sido la de la implantación de los ejidos, es decir, las tierras de uso público a extramuros de la "traza" y dependientes del fundo legal de la ciudad española, que, inevitablemente, suponían una intrusión en los solares vecinales -tanto terrestres como acuáticos- de la comunidad indígena. No está de más recordar que los tenochcas padecían a causa de ello y por la propia implementación de la "traza española", una considerable restricción espacial dentro de la isla. Llegados a este punto, cabe insistir en que, según la probanza de 1556, existían opiniones confusas y contradictorias acerca de si el "albarradón de las Atarazanas" era una simple reedificación de un resguardo indígena que se fechaba de la época del huey tlahtoani Ahuitzotl (c. 1486-1502), o si, por el contrario, era una obra original cuyo trazo seguía de cerca este antecedente constructivo precortesiano. A ese respecto, resulta interesante reproducir la declaración de Ángel de Villafaña, testigo español que comentó:

\footnotetext{
${ }^{82}$ Probanza hecha en México a pedimiento del fiscal aquella Audiencia sobre el edificio de la albarradaa y desaguadero de aquella ciudad, 1556. AGI-Patronato, 181, Ro. 30, ff. 992v-1045r, citado por Pérez Rocha, 1996.

${ }^{83}$ AGI-Patronato, 181, R o. 30, ff. 992v-1045r, f. 998r, citado por Pérez-Rocha, 1996, pp. 43-44. Cursiva del autor.
} 
De pueblos a barrios: reconfiguraciones espaciales y administrativas en la frontera...

[...] A la quarta pregunta dixo que a este testigo le paresçe que al tiempo que se conquistó esta çiudad < de México>, o días después, estaba hecha vn albarrada por donde al presente se haze o muy çerca de ella, la qual tenían hecha los yndios desta çiudad para defensa del daño que podían reçebir de la dicha laguna $[\ldots]^{84}$.

Las esclarecedoras palabras de este testigo de origen peninsular invitan a considerar la posibilidad de que los operarios maceguales -instruidos bajo las estrictas indicaciones del alguacil de obras, de los señores y principales tenochcas y del juez Esteban de Guzmán ${ }^{85}$ - hubiesen construido una albarrada unos metros más adentro de la raya que seguía la antigua, ganando unos terrenos en el lago que se iban a desecar. Al mismo tiempo, y empezando desde la calzada que conducía al cerro del Tepeyac por el norte, la albarrada estaba prevista para que llegase a cerrar hasta la calzada de Iztapalapa por el sur. Ello habría ocasionado también la encapsulación, dentro de esta nueva topografía insular, de los islotes chinamperos meridionales y con carácter conurbano que son motivo de discusión aquí, y que, como estamos viendo, hasta la década de 1550 habían mantenido una relación especial de sujeción jurídica y administrativa con los gobernadores tenochcas. Es preciso comentar que no existen evidencias cartográficas fehacientes que justifiquen la presencia de un antecedente en el tramo meridional de esta albarrada para antes de las obras hidráulicas asociadas a esta catastrófica inundación. Lo que suscribe el carácter original que tendría este albarradón. En el Mapa de Uppsala (c. 1550), este perímetro sureño aparece insinuado tan solo como un difuso camino de tierra batida o bien como un torrente sin agua en temporada seca $^{86}$. Con ello se refrendaría una vez más que, antes de 1555 y 1556, Zoquipan y Toltenco no fueron espacios incorporados plenamente a la isla de México.

Figura 4. (Sin llamada específica en el texto). El límite oriental de la isla de México con anterioridad y posterioridad a las obras del albarradón de las Atarazanas. Se señala, en negro,

la superficie reservada a la traza española dentro de la isla.

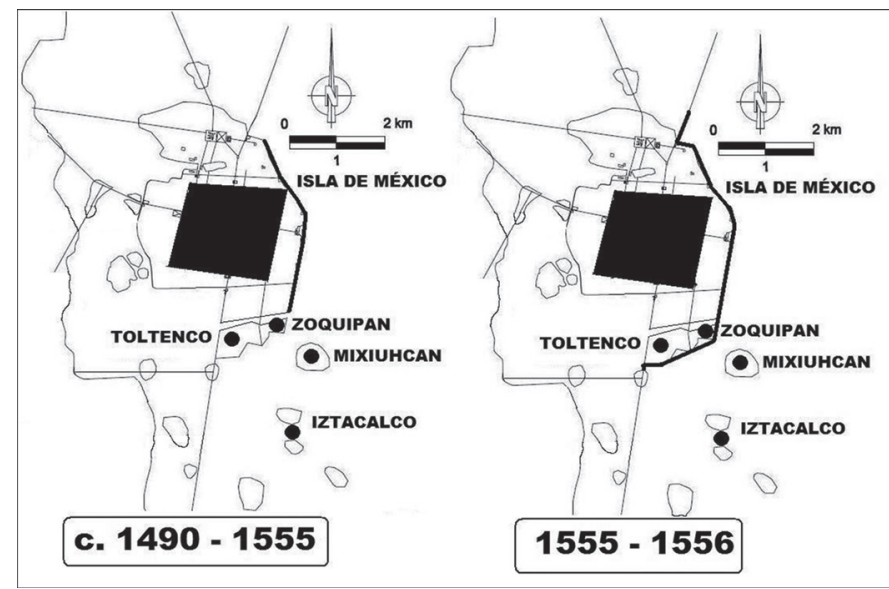

Fuente: diseño del autor.

\footnotetext{
${ }^{84}$ Ibid., ff. 992v-1045r, f. 1025v; citado por Pérez-Rocha, 1996, p. 102. Cursiva del autor.

${ }^{85}$ Ibid.

${ }^{86}$ Mapa de Uppsala (c. 1550).
} 
Respecto a este último, disponemos de una evidencia documental impresa en una copia de la sentencia dictada por el juez Esteban de Guzmán, en 1555, a favor de Ana Nencihuatl como legítima poseedora de una casa y diez camellones chinamperos en Zoquipan. Dicho documento fue incorporado como material probatorio en el litigio que, ya en 1571, enfrentó a esta beneficiaria con varios de los principales de la parcialidad de San Pablo. Sin embargo, en la versión náhuatl que acompañaba la correspondiente documentación en castellano, se manifestaba lo siguiente: "yc moteilhuico yn oncan mani ytocayocan Zoquipan [...]" ${ }^{\text {87 }}$. Es decir: " $<$ Ana Nencihuatl $>$ Yso agrabio

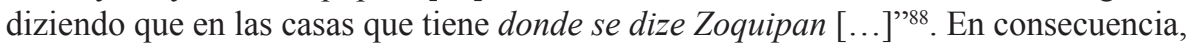
en fechas tan significativas como 1555 Zoquipan es referido aún como "parte" y no como barrio o tlaxilacalli. Por su parte, Toltenco, años más tarde, suscitaría todavía una poco conveniente ambigüedad. En una demanda interpuesta en 1564 por Pablo Macuex -residente indígena del aledaño tlaxilacalli de Tlachcutitlan- contra Ana Xoco, el escribano de la Real Audiencia que transcribió la información aportada por un testigo presentado por el primero, anotaba significativamente lo siguiente: “[...] Testigo Pablo Matian natural del <tachado: pueblo> de Toltengo testigo susodicho, aviendo jurado en forma de derecho por dios nuestro señor de decir verdad [...]" ${ }^{\prime 89}$.

\title{
Toltenco y Zoquipan en la segunda mitad del siglo XVI
}

A partir de 1556, cuando el albarradón estuvo ya levantado, la fisonomía de la isla de México había cambiado notablemente en su límite meridional. Un tramo de esta construcción, giraba a la altura del islote de Mixiuhcan, para dirigirse, de este a oeste, hacia el cierre con la calzada de Iztapalapa. Así, la Ciudad de México quedaba completamente resguardada de los invites que el crecimiento de la laguna pudiese ocasionar. Y la república de naturales de Tenochtitlan definía territorialmente su suelo y área de influencia. Es precisamente en ese año de 1556, y no antes, cuando Toltenco y Zoquipan empiezan a participar en el coatequitl de obra pública tributado a la Corona y en el sistema de repartimiento de indios. Y, no sorpresivamente, lo hacen en calidad de barrios de San Pablo - contentando, de ese modo, a las autoridades concejiles tenochcas-, pero también trabajando en el Hospital Real de Indios, institución de origen franciscano:

\begin{abstract}
Yten $<$ en 1556> se traxeron para el hospital Real este dho. año mil e 6 çientas cargas de cal de çumpango e se pago por la trayda a $\mathrm{m}^{\circ}$. rreal por cada una carga e la traxeron los yndios de los quatro barrios desta çibdad e los yndios de los barrios de gueguecalco moyotla texcalcoculco y atlanpa e tlalcocomulco y amanalco e tepetitlan tequixquipan necaltitlan xoloco acatlan tetepilco yaotlica tescaltitlan tlaxquytitlan tultengo huyçinaguatongo temazcaltitlan çoquipan oçelotzontecontitlan ometochtitlan contzingo tomatlan coatlan çacatlan aguatongo quytlaguacatongo teocaltitlan tzaqualco cotolco tlocanpan populco cuepopan $[\ldots]^{90}$.
\end{abstract}

\footnotetext{
${ }^{87}$ AGN-Tierras, vol. 32, exp. 1, f. 10r, citado por Reyes García, et al. (paleog. y ed.), 1996, p. 137. Nocursiva del autor.

${ }^{88}$ Ibid. Cursiva del autor.

${ }^{89}$ AGN-Tierras, vol. 55, exp. 5, f. 10r, citado por Reyes García, et al. (paleog. y ed.), 1996, p. 240. Cursiva del autor.

${ }^{90}$ AGN-Civil, vol. 644, exp. 1, ff. 145r-173v, f. 147r. Cursiva del autor.
} 
De pueblos a barrios: reconfiguraciones espaciales y administrativas en la frontera...

El análisis detallado de las actividades en las que Toltengo y Zoquipan emitieron cuadrillas de trabajadores para el coatequitl de obra pública durante el ciclo 15551564/1565, dilucida claramente que estos antiguos pueblos fueron ocupados prioritariamente en las obras del citado Hospital Real de Indios, de San José de los Naturales, del convento de San Francisco y del tecpan calli o casa de comunidad de la república indígena de Tenochtitlan:

Tabla 1. Actividades laborales realizadas por las tandas de operarios maceguales de Toltenco durante el ciclo 1555-1564/1565.

\begin{tabular}{|l|l|}
\hline 1556 & Cargas de cal para el Hospital Real de Indios \\
\hline 1557 & Transporte de estacas de madera \\
\hline 1558 & Cargas de cal para el Hospital Real de Indios \\
\hline 1559 & Cargas de cal para San Francisco y San José de los Naturales \\
\hline 1561 & Cargas de cal para el Hospital Real de Indios \\
\hline
\end{tabular}

Fuente: AGN-Civil, vol. 644, exp.1, ff. 145r-173v, ff. 147r, 148v, 160v, 162r, 166r.

Tabla 2. Actividades laborales realizadas por las tandas de operarios maceguales de Zoquipan durante el ciclo 1555-1564/1565.

\begin{tabular}{|l|l|}
\hline 1556 & Cargas de cal para el Hospital Real de Indios \\
\hline 1558 & Cargas de cal para el Hospital Real de Indios \\
\hline 1559 & Cargas de cal para la fundición de la ciudad \\
\hline 1560 & Cargas de cal para el Hospital Real de Indios \\
\hline 1561 & Cargas de cal para el juzgado y casa pública (tecpan calli) \\
\hline 1562 & Cargas de cal para el juzgado y casa pública (tecpan calli) \\
\hline 1562 & Cargas de cal para las casas del oidor Ceinos \\
\hline
\end{tabular}

Fuente: AGN-Civil, vol. 644, exp. 1, ff. 145r-173v, ff. 147r, 160v, 162r, 164v, 166v, 169r, 169v.

A tenor de la información contenida en las tablas anteriores, resulta evidente que, tras 1561 y 1562, Toltenco y Zoquipan no aparecen ya enlistados individualmente en los llamamientos de obra pública y otros servicios. Muchas de las extracciones laborales registradas desde entonces, y hasta el advenimiento del año 1565, se enmascarán en la fórmula elusiva de "[...] e lo traxeron//llevaron los quatro barrios por obra pu.ca e coatequytl [... $]^{\prime 91}$. Esta aparente parálisis en los servicios de trabajo colectivo de escasa y baja calificación que hasta entonces Toltenco y Zoquipan habían aportado a las instalaciones del cabildo indio y a los padres franciscanos coincidió, sospechosamente, con los años en los que el prelado Alonso de Montúfar reforzaba la presencia de provisores de indios en la parcialidad de San Pablo ${ }^{92}$. Es probable que no exista la detención en las emisiones de cuadrillas de trabajadores que esta documentación administrativa y oficial parece insinuar; lo más probable es que ambos lugares continuaran trabajando, pero a las órdenes de los agentes arzobispales:

\footnotetext{
${ }^{91}$ AGN-Tierras, vol. 644, exp. 1, ff. 145r-173v, ff. 171r, 171v, 172r.

${ }^{92}$ ENE, vol. IX, p. 161; Códice Osuna, 1565, f. 8v; Anales de Juan Bautista, 2001 (1582), p. 193.
} 
Yten, en este año [de 1564] se gastaron treinta y seys morillos viexos cortos para adereçar la puente de la açequia rreal desta çibdad que es donde se rreparte la yerba en el barrio de san pablo por obra pu.ca e coatequytl e hizieronlo los del dho. barrio $[\ldots]^{93}$.

En ese sentido, no resulta extrañoque la secularización final de la doctrina de San Pablo tuviese lugar el 14 de enero de 1565, cuando se "teatralizó" la expulsión definitiva de los religiosos seráficos, y se dio la consiguiente re-ocupación seglar ${ }^{94}$. Uno de los visitadores y provisores de esta nueva parroquia -sufragánea, desde 1568, del distrito de la Iglesia Mayor- fue Alonso Fernández de Sigura, quien en 1570 expresaba sus inquietudes acerca de que tan cierto era que los barrios alejados de la cabecera de San Pablo - como serían estos antiguos pueblos de Toltenco, Zoquipan o Mixiuhcan- exhibiesen aún un bajo nivel de evangelización, atribuible, quizás, a su reciente incorporación a la república de naturales de Tenochtitlan como vecindarios con trabajadores pobres y poco especializados:

[...] en la visita que he hecho en San Pablo [...] he hallado muchos indios e indias que no saben persignarse, ni ninguna de las cuatro oraciones que manda la iglesia $[\ldots .$. . La causa pienso puede ser la inobediencia de no querer acudir á las parroquias que les están señaladas en esta ciudad $[\ldots]^{95}$.

No obstante, en 1575, la parcialidad de San Pablo pasaría de nuevo al control del clero regular con la transferencia que el virrey Enríquez de Almansa hizo de ella a la Orden de San Agustín ${ }^{96}$.

\section{Las vicisitudes de Iztacalco en la segunda mitad del siglo XVI}

Iztacalco tuvo un destino un tanto disímil al caso descrito para Toltenco y Zoquipan. Esta comunidad insular quedó a extramuros del albarradón de las Atarazanas que se construyó entre 1555 y 1556, fue secularizada desde ese último año y las pretensiones de reconvertirlo en un barrio extra-urbano - dependiente de San Pablo por las relaciones sociopolíticas que se arrastraban desde le época prehispánicadentro de la república de naturales de la capital de la Nueva España se vieron fuertemente frustradas desde el principio. A diferencia de los otros dos antiguos pueblos, Iztacalco exhibió una de las ratios más irrisorias en la aportación de cuadrillas de trabajadores que se recogen en la relación oficial del coatequitl de obra pública durante el ciclo 1555-1564/1565. A pesar de que siempre lo hizo en calidad de barrio, nunca trabajó para el cabildo indígena ni para las instituciones franciscanas,pues fue ocupado convenientemente en los requerimientos del virrey y de la Real Audiencia:

\footnotetext{
${ }^{93}$ AGN-Tierras, vol. 644, exp. 1, ff. 145r-173v, f. 172v.

${ }^{94}$ Anales de Juan Bautista, 2001 (1582), p. 301.

${ }^{95}$ Descripción del Arzobispado de México, 1897 (1570), p. 278.

${ }^{96}$ Códice Aubin, 1576, f. 59v.
} 
De pueblos a barrios: reconfiguraciones espaciales y administrativas en la frontera...

Tabla 3. Actividades laborales realizadas por las tandas de operarios maceguales de Iztacalco durante el coatequitl de obra pública del ciclo 1555-1564/1565.

\begin{tabular}{|l|l|}
\hline 1556 & Cargas de cal para los reparos de la casa real \\
\hline 1557 & Estacas y tezontle para las casas del virrey \\
\hline 1561 & Cargas de cal para los reparos de las casa del oidor Dr. Orozco \\
\hline
\end{tabular}

Fuente: AGN-Civil, vol. 644, exp. 1, fols. 145r-173v: fols. 147r-147v, 148v, 165v.

Además, la estancia contaba con clérigos que administraban los sacramentos, como era el caso de Francisco de Manjarres ${ }^{97}$. Todo ello pudo influir para que, en 1566, Iztacalco, aprovechando que no había gobernador a la cabeza del consistorio indígena en la Ciudad de México $^{98}$, se viese con la suficiente fuerza para provocar un conato de emancipación definitiva de Tenochtitlan y para erigirse en comunidad o en república de naturales por derecho propio:

[...] Y entonces -en enero de 1566- también fueron atados los de Iztacalco, allá arriba fueron tomados presos a causa de que querían poner gobernador donde vivían ya que // hacía ya un poco de tiempo que estaban aparte y por esta causa fueron atadas 25 personas de Iztacalco. [...] Sábado a 2 días del mes de marzo de 1566 años, entonces fueron a acarrear a la gente de Iztacalco, fue en persona el alcalde Miguel Sánchez que llevó a muchos topiles. El día anterior allá maltrataron al alguacil mayor - de Tenochtitlan- que iba a impedirles (lo que hacían) y sólo allá en manos de los iztacalcas fue a caer $[\ldots]^{99}$.

Hasta donde se sabe, estos turbulentos años en Iztacalco parecen haber acabado tras la llegada de los jueces gobernadores: Francisco Jiménez (1568/1568-1573) y Antonio Valeriano (1573-c. 1599) al frente de la república tenochca. El último asistió al traspaso de la parcialidad de San Pablo a los frailes agustinos en 1575. A partir de este postrero tercio del siglo XVI, Iztacalco mantuvo sus relaciones de dependencia y de sometimiento administrativo con respecto a Tenochtitlan, por bien que la naturaleza de dicha vinculación continuara siendo, tras los funestos enfrentamientos de 1566, necesariamente confusa e indeterminada:

[...] don alvarado etl por cuanto el concejo y comun de esta estancia de yztacalco san matia [s] sujeta a esta ciudad de mexico de la parte de san juan tenuchtitlan $[\ldots]^{100}$.

[...] don luys de velasco hago saver a vos el juez repartidor de las partes de san juan y santiago desta ciudad que los n.(aturales) de la estancia y barrio de yztacalco me han hecho rrelacion que $[\ldots]^{101}$.

\footnotetext{
${ }^{97}$ Descripción del Arzobispado de México, 1897 (1570), p. 278.

${ }^{98}$ Recordamos que don Luis de Santa María Cipactzin, último gobernador legítimo de México-Tenochtitlan, murió en 1565 (Códice Aubin, 1576, f. 54v.)

${ }^{99}$ Anales de Juan Bautista, 2001 (1582), pp. 137 y 143. Cursiva del autor.

${ }^{100}$ AGN-Indios, vol. 4, exp. 29, f. 8v (año 1589). Cursiva del autor.

${ }^{101}$ AGN-Indios, vol. 3, exp. 269, f. 63r (año 1590). Cursiva del autor.
} 


\section{Conclusiones}

Lejos de ser centros campesinos completamente sumisos a las órdenes de MéxicoTenochtitlan, los pueblos de Iztacalco, Toltenco, Zoquipan y Mixiuhcan, han emergido, tras el estudio presentado aquí, como asentamientos dinámicos, que, tras la Conquista, y en un momento muy determinado del siglo XVI, pudieron haber llegado a tener la oportunidad de buscar múltiples estrategias para desembarazarse definitivamente de su estatus de sujetos y convertirse en cabeceras independientes. Al hacer una sucinta recapitulación, podemos subrayar que los habitantes de estos centros, anexos a la frontera natural que la isla de México tenía por el sur, estuvieron vinculados por fuertes lazos de dependencia clientelar y servil hacia los señores de Tenochtitlan en la época prehispánica. Estas relaciones interpersonales asimétricas eran las que, en definitiva, promovían en dicha zona, una construcción cognitiva que elaboraba el espacio como un continuum campo-ciudad. A la luz de los datos aportados, parece probable que la situación se perpetuase, tras la Conquista, hasta la década de 1550. Fue en este momento en el que el cabildo de México-Tenochtitlan, y también los padres franciscanos, territorializaron las relaciones de poder, persuadiendo o forzando a las estancias de terrazgueros a convertirse en barrios adscritos y en visitas vecinales adeptas a cada una de las cuatro cabeceras doctrinales seráficas. Muy probablemente, la construcción del albarradón de las Atarazanas, en 1555-1556, contribuyó, mediante la remodelación de la topografía insular que aconteció con ello, a este respecto. Los pueblos que quedaron a intramuros de esta obra de ingeniería -es decir, Toltenco, Zoquipan y parcialmente Mixiuhcan- perdieron, de forma irremediable, la capacidad de tener un gobierno autónomo y se acabaron convirtiendo en barrios o tlaxilacaltin de los tenochcas. A fuera de la albarrada, Iztacalco, al haber establecido una frontera identitaria más vigorosa frente a Tenochtitlan, solo pudo gozar brevemente, en 1566, de sus ansias de convertirse en república por derecho natural.

\section{Fuentes}

\section{Fuentes Primarias}

\section{Archivos}

Archivo General de la Nación (AGN)-Civil, vol. 644, exp. 1, ff. 145r-173v. Memorial de los gastos que han hecho el governador y principales en las obras públicas desde el principio del año 55 hasta el de 65. (1565). Inserto en Los yndios offiçiales de la parte de mexico en la querella que tenemos dada contra los alcaldes y rregidores (Ciudad de México, 1564-1568, pleito).

AGN-Civil, vol. 644, exp. 1, ff. 95-97v. La residençia de don Esteban. (1554/15551557). Inserto en Los yndios offiçiales de la parte de mexico en la querella que tenemos dada contra los alcaldes y rregidores (Ciudad de México, 1564-1568, pleito).

AGN-Indios, vol. 3, exp. 269, f. 63r. Para que el juez repartidor vea la cantidad de yndios de servicio que da la parte de san juan y que la dicha estançia de iztacalco 
De pueblos a barrios: reconfiguraciones espaciales y administrativas en la frontera...

de los ciento y setenta y tres tributarios (Ciudad de México, 1590, mandamiento del virrey Luis de Velasco y Castilla).

AGN-Indios, vol. 4, exp. 29, f. 8r. Para que conforme al parecer del juez gobernador de la parte de San Juan Tenochtitlan pueda componer la ermita de los Santos Reyes [en Iztacalco] (Ciudad de México, 1589, mandamiento del virrey Álvaro Manrique de Zúñiga).

AGN-Mercedes, vol. 4, exp. 118, f. 35v. Comision a don esteban de guzman governador de suchimilco para tomar rresidençia al governador, allcdes. y rregidores y prençipales desta çiudad de la parte de mexico (Ciudad de México, 15 de junio de 1554, mandamiento del virrey Luis de Velasco y Ruiz de Alarcón).

AGN-Tierras, vol. 20, $2^{\mathrm{a}}$ parte, exp. 4, 12 ff. Maria Techo contra Maria Tlaco por tierras (Ciudad de México, 1563, pleito).

AGN-Tierras, vol. 24, exp. 3, ff. 107r-233v. Atlixuca Tepetlazingo-barrio en el camino de Ixtapalapa. Autos seguidos por Luis de Avila Bezos, contra los naturales de dicho barrio sobre una casa y siete suertes de tierras llamadas mexicatlalli. (Ciudad de México, 1569, pleito).

AGN-Tierras, vol. 37, exp. 2, ff. 77v-94v. Testamento de Hernando de Tapia (1555). Inserto en La muger y herederos de Hernando de Tapia con el barrio de San Juan por casas en San Pablo (Ciudad de México, 1576, pleito).

AGN-Tierras, vol. 46, exp. 4, ff. 386r/1r - 432r/46r. Maria Juana yndia e todos sus consortes contra el colegio de san pablo de esta çiudad sobre ciertas tierras de una capellanía. (Ciudad de México, 1581, pleito).

Benson Latin American Collection (BLAC) Universidad de Texas-Colección Genaro García, Ms. 30, 10 ff. Cargo y descargo que los macehuales de los cuatro barrios de México hacen a don Diego ante el juez don Esteban de Guzmán. Año 1553 (Sic). (1554).

BLAC-Colección Genaro García, Ms. 42, 23 ff. Códice indígena de 1564-1565. Libro de gastos de la comunidad de la Ciudad de México.

Biblioteca Nacional de Francia (BNF)-Fonds Mexicain, Ms. 150, 1f. Tenochtitlan Corte de los Emperadores Mexicanos.

\section{Libros}

(Sin datos). Descripción del Arzobispado de México. 1570. México D. F.:Imprenta de J.J. Terrazas e Hijas, 1897.

Bejarano, Ignacio (ed.). Actas de cabildo de la Ciudad de México. Libros I-II (15241532). Ciudad de México: Municipio Libre, 1889. 
Berdan, Frances F. y Anawalt, Patricia (eds.). Códice mendocino (1542). Berkeley: University of California Press, 1997.

Celestino, Eustaquio y Reyes García, Luis (paleog., trad. y ed.). Anales de Tecamachalco (1590). México D.F: Centro de Investigaciones y Estudios Superiores en Antropología Social (Colección Puebla Series), 1992.

Del Paso y Troncoso, Francisco (ed. y recop.). Epistolario de la Nueva España, 1505 1818, 16 volúmenes. México D. F.: Editorial Porrúa, 1940.

García, Luis, et al. (paleog. y ed.). Documentos nauas de la Ciudad de México del siglo $X V I$. México D. F.: Centro de Investigaciones y Estudios Superiores en Antropología Social-Archivo General de la Nación, 1996.

Obadia-Baudesson, Paule (ed.). Historia de los mexicanos por sus pinturas (c. 1535). París: Association Oxomoco et Cipactonal, 1988.

\section{Capítulos de libros}

(Sin datos). "Anales de Juan Bautista (1582)”, en Reyes García, Luis (paleog., trad. y ed.), ¿Cómo te confundes? ¿Acaso no somos conquistados? Anales de Juan Bautista. México D.F.: Centro de Investigaciones y Estudios Superiores en Antropología Social- Biblioteca Lorenzo Boturini de la Insigne y Nacional Basílica de Guadalupe (Colección Historias), 2001.

(Sin datos). "Códice Aubin (1576)", en Códice Aubin. Manuscrito azteca de la Biblioteca Real de Berlín. México D. F.: Secretaría de Fomento, 1902.

(Sin datos). "Códice Cozcatzin (1572)", en Valero de García Lascuráin, Ana Rita (ed.), Los códices de Ixhuatepec. Un testimonio pictográfico de dos siglos del conflicto agrario. México D. F.: Centro de Investigaciones y Estudios Superiores en Antropología Social-Colegio de San Ignacio de Loyola/Vizcaínas, 2004.

(Sin datos). "Códice Osuna (1565)", en Cortés Alonso, Vicenta (paleog. ed. y est.), Pintura del gobernador, alcaldes y regidores de México, 2 volúmenes. Madrid: Ministerio de Educación y Cultura, 1973-1976.

(Sin datos). "Mapa de Uppsala (c. 1550)", en León-Portilla, Miguel y Aguilera, Carmen (ed.), Mapa de México-Tenochtitlan y sus contornos hacia 1550. México D. F.: Celanese Mexicana, 1986.

Ramírez de Fuenleal, Sebastián. "Carta á S.M. del Obispo de Santo Domingo, don Sebastián Ramírez de Fuenleal, presidente de la Audiencia de Méjico, manifestando su parecer acerca de la perpetuidad y población de aquella tierra. 10/07/1532”, en Colección de documentos inéditos relativos al descubrimiento, conquista y colonización de las antiguas posesiones españolas en América y Oceanía. Tomo XIII. Madrid: Imprenta de José María Pérez, 1870 (1532). 
De pueblos a barrios: reconfiguraciones espaciales y administrativas en la frontera...

Reyes García, Luis. "El término calpulli en documentos del siglo XVI", en Reyes García, Luis, et al. (paleog. y ed.), Documentos nauas de la Ciudad de México del siglo XVI. México D. F.: Centro de Investigaciones y Estudios Superiores en Antropología Social-Archivo General de la Nación, 1996.

\section{Fuentes secundarias}

\section{Libros}

Battcock, Clementina. Construcciones y significaciones de un hecho histórico: la guerra entre México-Tenochtitlan y Azcapotzalco. Saarsbrücken: Editorial Académica Española, 2011.

Berdan, Frances F., et al. (ed.). Aztec Imperial Strategies. Washington: Dumbarton Oaks, 1996.

Bernal, Ignacio. Tenochtitlan en una isla. México D. F.: Secretaría de Educación Pública (Colección SEP - Setentas), 1984 [1974].

Carrasco, Pedro. Estructura político-territorial del Imperio tenochca. La Triple Alianza de Tenochtitlan, Tetzcoco y Tlacopan. México D. F.: El Colegio de México-Fondo de Cultura Económica (Sección Obras de Historia), 1996.

Castañeda de la Paz, María. Conflictos y alianzas en tiempos de cambio: Azcapotzalco, Tlacopan, Tenochtitlan y Tlatelolco (siglos XII al XVI). México D.F.: Instituto de Investigaciones Antropológicas-Universidad Nacional Autónoma de México, 2013.

Chauvet, Fidel de Jesús. Los franciscanos en México, 1523-1980. México D. F.: Servicio de Publicaciones de la Provincia del Santo Evangelio de México, 1981.

Chimalpahin, Domingo Francisco de San Antón Muñón. Annals of His Time: Don Domingo de San Antón Muñón Chimalpahin Quauhtlehuanitzin (edición en inglés a cargo de Lockhart, James, et al.). Stanford: Stanford University Press, 2006 [c. 1620].

Chimalpahin, Domingo Francisco de San Antón Muñón. Codex Chimalpahin (edición en inglés cargo de O. J. Anderson, Arthur y Schroeder, Susan). Norman: University of Oklahoma Press (Colección The Civilization of American Indian Series), 1997 [c. 1620].

Cook, Sherburne F. y Simpson, Lesley B. The Population of Central Mexico in the Sixteenth Century. Berkeley-Los Angeles: University of California Press (Colección Ibero-Americana), 1948.

Cortés, Hernán. Cartas de relación. Madrid: Dastin (Colección Historia/Crónicas de América), 2000 (1519-1526). 
Durán, Diego. Historia de las Indias de Nueva España e Islas de Tierra Firme. México D. F.: Imprenta de Andrade y Escalante, 1897 [1581].

Frémont, Armand. La région, espace vécu. París: Flammarion,»1970.

García Quintana, Josefina y Romero Galván, José Rubén. México Tenochtitlan y su problemática lacustre. México D. F.: Instituto de Investigaciones HistóricasUniversidad Nacional Autónoma de México, 1978.

Gibson, Charles. Los aztecas bajo el dominio español, 1519-1810. México D. F.: Siglo veintiuno (Colección América Nuestra), 1986 [1964].

González Aparicio, Luis. Plano reconstructivo de la región de Tenochtitlan. México D.F.: Instituto Nacional de Antropología e Historia, 1973.

Hassig, Ross. Trade, Tribute, and Transportation. The Sixteenth-Century Political Economy of the Valley of Mexic. Norman: University of Oklahoma Press, 1985.

Kellogg, Susan. Law and the Transformation of Aztec Culture, 1500-1700. Norman: University of Oklahoma Press, 2005 [1995].

Kobayashi, Munehiro. Tres estudios sobre el sistema tributario de los mexicas. México D. F.: Centro de Investigaciones y Estudios Superiores en Antropología Social, 1993.

Lira, Andrés. Comunidades indígenas frente a la ciudad de México. Tenochtitlan y Tlatelolco, sus pueblos y barrios (1812-1919). México D. F.: El Colegio de México, 1983.

Lockhart, James. The Nahuas after the Conquest. A Social and Cultural History of the Indians of Central Mexico, Sixteenth through Eighteenth Century. Palo Alto: Stanford University Press, 1992.

Lockhart, James. We People Here: Nahuatl Accounts of the Conquest of México. Berkeley: University of California Press, 1993.

Lombardo de Ruiz, Sonia. Desarrollo urbano de México-Tenochtitlan, según las fuentes documentales. México D. F.: Secretaría de Educación Pública- Instituto Nacional de Antropología e Historia, 1973.

López de Gómara, Francisco. La Conquista de México. Madrid, Dastin (Colección «Crónicas de América»), 2003 [1552].

Martínez, Hildeberto. Tepeaca en el siglo XVI: Tenencia de la tierra y organización de un señorío. México D.F.: Secretaría de Educación Pública-Centro de Investigaciones y Estudios Superiores en Antropología Social (Ediciones de la Casa Chata), 1984. 
De pueblos a barrios: reconfiguraciones espaciales y administrativas en la frontera...

Mazzetto, Elena. Lieux de culte et parcours cérémoniels dans les fêtes des vingtaines à Mexico-Tenochtitlan. Oxford: Archaeopress-BAR Series, 2014.

Mendieta, Jerónimo. Historia eclesiástica indiana. Barcelona: Linkgua Ediciones, 2012 [1596].

Molina, Alonso de. Aquí comienza un vocabulario en la lengua Castellana y Mexicana, Compuesto por el muy reverendo fray Alonso de Molina: Guardián del convento de sant Antonio de Tetzcuco de la orden de los frayles Menores. Ciudad México: Casa de Juan Pablos, 1555.

Molina, Alonso de. Vocabulario en lengua castellana y mexicana. Ciudad de México: Casa de Antonio Spinola, 1571.

Motolínia, Toribio de Benavente. Carta al emperador Carlos V. Barcelona: Linkgua Ediciones, 2012 [1555].

Mundy, Bárbara. The Death of Aztec Tenochtitlan, the Life of Mexico City. Austin: University of Texas Press, 2015.

Nybo Rasmussen, Jorgen. Fray Jacobo Daciano. Zamora (México): El Colegio de Michoacán, 1992.

O'gorman, Edmundo. Destierro de sombras. Luz en el origen de la imagen y culto de Nuestra Señora de Guadalupe en el Tepeyac. México D. F.:Universidad Nacional Autónoma de México, 1986.

O’gorman, Edmundo. Guía de las actas de cabildo de la ciudad de México, siglo XVI. México D.F.: Fondo de Cultura Económica, 1970.

Ouweneel, Arij y Hoekstra, Rik. Las tierras de los pueblos de indios en el Altiplano de México, 1560-1920. Una aportación teórica interpretativa. Ámsterdam: Centro de Estudios y Documentación Latinoamericanos, 1998.

Palerm, Ángel (ed.). Obras hidráulicas prehispánicas en el sistema lacustre del valle de México. México D. F.: Secretaría de Educación Pública-Instituto Nacional de Antropología e Historia, 1973.

Pérez Rocha, Emma. Ciudad en peligro. Probanza sobre el desagüe general de la ciudad de México, 1556. México D.F.: Instituto Nacional de Antropología e Historia, 1996.

Rojas Gutiérres de Gandarilla, José Luis de. México-Tenochtitlan: Economía y sociedad en el siglo XVI. México D. F.: Fondo de Cultura Económica, 1986.

Rojas Gutiérres de Gandarilla, José Luis de. Tenochtitlan: Capital of the Aztec Empire. 
Gainesville: University of Florida Press (Colección Ancient Cities of the New World), 2012.

Rojas Rabiela, Teresa, et al. Nuevas noticias sobre las obras hidráulicas prehispánicas y coloniales en el Valle de México. México D.F.: Secretaría de Educación PúblicaCentro de Investigaciones y Estudios Superiores en Antropología Social, 1974.

Sahagún, Bernardino de. Historia general de las cosas de la Nueva España. Madrid: Dastin (Colección Historia / Crónicas de América), 2001 [1577].

Sander, William T., et al. The Basin of Mexico: Ecological Processes in the Evolution of a Civilization. Nueva York: Academic Press, 1979.

Schroeder, Susan. Chimalpahin and the Kingdoms of Chalco. Tucson: University of Arizona Press, 1991.

Smith, Michael E. The Aztecs. Malden: Blackwell Publishing, $2003 a$.

Ternaux-Compans, Henri. Cruautés horribles des conquérants du Mexique, Mexico 1829. París: Arthus Bertrand Libraire-Éditeur, 2011 [1838].

Alvarado Tezozomoc, Hernando de. Crónica mexicana. Madrid: Dastin (Colección Historia/Crónicas de América), 2001 [1598].

Alvarado Tezozomoc, Hernando de. Crónica mexicayotl. México D. F.: Instituto de Investigaciones Históricas-Universidad Nacional Autónoma de México (Colección Primera Serie Prehispánica), 1998 [c. 1598-1609].

Touissant, Manuel, et al. Planos de la Ciudad de México, siglos XVI y XVII. México D. F.: Instituto de Investigaciones Estéticas-Universidad Nacional Autónoma de México, 1938.

Touraine, Alain. Can We Live Together? Stanford: Stanford University Press, 2000.

Touraine, Alain. Critique of Modernity. Oxford: Blackwell Publishing, 1995.

Touraine, Alain. The Voices and the Eye. Cambridge: Cambrige University Press, 1981.

\section{Capítulos de libros}

Alcántara, Alejandro. "Los barrios de Tenochtitlan. Topografía, organización interna y tipología de sus predios" en González Aizpuru, Pilar y Escalante, Pablo, Historia de la vida cotidiana en México (tomo I: Mesoamérica y los ámbitos indígenas de la Nueva España). México D. F.: Fondo de Cultura Económica, 2004.

Bernal, María Elena y García, Ángel J. “El altepetl y sus antecedentes prehispánicos: 
De pueblos a barrios: reconfiguraciones espaciales y administrativas en la frontera...

contexto teórico-historiográfico", en Fernández Christlieb, Francisco y García Zambrano, Ángel J. (coords.). México D. F.: Fondo de Cultura Económica, Instituto de Geografía-Universidad Nacional Autónoma de México, 2006.

Calnek, Edward E. "Conjunto urbano y modelo residencial en Tenochtitlan", en Clanek, Edward E., et al. (eds.), Ensayos sobre el desarrollo urbano en México. México D. F.: Secretaría de Educación Pública, 1974.

Calnek, Edward E. "Tenochtitlan-Tlatelolco: the Natural History of a City", en Sanders, William T., et al. (eds.), Urbanism in Mesoamerica, vol. I. México D. F.: University Park-Instituto Nacional de Antropología e Historia-Pennsylvania University Press, 2003.

Calnek, Edward E. "The Internal Sructure of Tenochtitlan”, en Wolf, Erick R. (ed.), The Valley of Mexico: Studies in Prehispanic Ecology and Society. Albuquerque: University of Mexico Press, 1976.

González Rul, Francisco. "La cerámica postclásica y colonial en algunos lugares de la ciudad de México y el área metropolitana", en Serra Puche, María del Carmen y Navarrette, Carlos (eds.), Ensayos de alfarería prehispánica e histórica de Mesoamérica. Homenaje a Eduardo Noguera Auza. México D. F.: Instituto de Investigaciones Antropológicas-Universidad Nacional Autónoma de México, 1988.

Hewson, Martin. “Agency”, en Mills, Albert J., et al. (eds.), Encyclopedia Of Case Study Research, vol. I. Thousand Oaks: SAGE Publications Inc., 2010.

Hicks, Frederick. "Gift and Tribute: Relations of Dependency in Aztec Mexico", en Claessen, Henri J. M. y Van de Velde, Peter (eds.), Early State Economics. New Brunswick: Transaction Publishers, 1991.

Hirth, Kenneth, G., "Incidential Urbanism: The Structure of the City in Prehispanic Central Mexico", en Marcus, Joyces y Sabloff, Jeremy A. (eds.), The Ancient City. New Perspectives on Urbanism in the Old and New World. Santa Fe (EUA): School for Advanced Research, 2009.

Montúfar, Alonso de. "Parecer sobre lo que toca a México y Santiago. México, 10 de abril de 1562", en Scholes, Frances F. y Adams, Eleonor B. (paleog. y eds.), Documentos para la historia del México colonial, vol. V. México D. F.: Editorial Porrúa, 1958 [1562].

Rovira Morgado, Rossend. "San Pablo Teopan: pervivencia y metamorfosis virreinal de una parcialidad indígena de la Ciudad de México", en Dávalos, Marcela (coord.), De márgenes, barrios y suburbios en la Ciudad de México, siglos XVI-XXI. México D.F.: Instituto Nacional de Antropología e Historia-Consejo Nacional para la Cultura y las Artes (Colección «Historia / Serie Logos»), 2012. 
Sánchez Vásquez, María de Jesús, et al. "Tenochtitlan y Tlatelolco durante el Posclásico Tardío", en López Wario, Luis Alberto (coord.), Ciudad excavada. Veinte años de arqueología de salvamento en la ciudad de México y su área metropolitana. México D. F.: Instituto Nacional de Antropología e Historia (Serie «Científica»), 2007.

Sanders, William T. "The population of Tenochtitlan-Tlatelolco", en Sanders, William T., et al. (eds.), Urbanism in Mesoamerica, vol. I. México D.F.: University ParkInstituto Nacional de Antropología e Historia-University of Pennsylvania Press, 2003.

Smith, Michael E. "Aztec City-States", en Hansen, Mogens Herman (ed.), A Comparative Study of Thirty City-States Cultures. Copenhagen: Real Academia Danesa de Ciencias y Letras, 2000.

Smith, Michael E. "Small polities in Postclassic Mesoamerica", en Smith, Michael E. y Berdan, Frances F. (eds.), The Postclassic Mesoamerican World. Salt Lake City: The University of Utah Press, 2003b.

\section{Artículos en revistas}

Calnek, Edward E. "Settlement Pattern and Chinampa Agriculture at Tenochtitlan", en American Antiquity, vol. XXXVII, n. ${ }^{\circ}$, Washington, Society for American Archaeology, 1972.

Caso, Alfonso. "Los barrios antiguos de Tenochtitlan y Tlatelolco", en Memoria de la Academia Mexicana de Historia, tomo XV, vol. 1, México D. F., Academia Mexicana de la Historia, 1956.

Díaz Rodríguez, Jorge Abraham. "Los suelos lacustres de la Ciudad de México", en Revista Internacional de Desastres Naturales, Accidentes e Infraestructura Civil, vol. VI, n. ${ }^{\circ}$ 2, San Juan de Puerto Rico, Universidad de Puerto Rico, 2006.

Fuchs, Stephan. "Beyond Agency", en Sociological Theory, vol. XIX, n. ${ }^{\circ}$, Washington, American Sociological Association, marzo de 2001.

Gibson, Charles. "Rotation of Alcaldes in the Indian Cabildo of Mexico City", en The Hispanic American Historical Review, vol. XXXIII, n. ${ }^{\circ}$ 2, Durham [EUA], Duke University Press, 1953.

Hicks, Frederick. "Subjects States and Tribute Provinces: The Aztec Empire in the Northern Valley of Mexico", en Ancient Mesoamerica, vol. III, n. ${ }^{\circ}$, Cambridge, Cambridge University Press, 1992.

León-Portilla, Miguel. "La autonomía indígena: Carta al Príncipe Felipe de los principales de México en 1554", en Estudios de Cultura Náhuatl, vol. XXXII, México D. F., Instituto de Investigaciones Históricas-Universidad Nacional Autónoma de México, 2001. 
De pueblos a barrios: reconfiguraciones espaciales y administrativas en la frontera...

Martos López, Luis Alberto y Pulido Méndez, Salvador. "Un juego de pelota en la ciudad de México", en Arqueología. Revista de Arqueología del INAH, Nueva Época, n. ${ }^{\circ}$ 1, México D. F., Instituto Nacional de Antropología e Historia, enero-junio 1989.

Mazzetto, Elena y Rovira Morgado, Rossend. "Sobre la orilla del agua: En torno a la dignidad de atenpanecatl y de ciertos espacios de culto a la diosa Toci en MéxicoTenochtitlan", en Cuicuilco. Revista de la ENAH, vol. XXI, n. ${ }^{\circ}$ 59, México D. F., Escuela Nacional de Antropología e Historia, enero-abril de 2014.

Megged, Amos. "Cuauhtemoc's Hiers", en Estudios de Cultura Náhuatl, vol. XXXVII, México D. F., Instituto de Investigaciones Históricas-Universidad Nacional Autónoma de México, 2007.

Moreno de los Arcos, Roberto, "Los territorios parroquiales de la ciudad arzobispal, 1325-1980", en Gaceta del Arzobispado de México, vol. XXII, n. ${ }^{9}$ 9-10, México D. F., Arzobispado de México, septiembre-octubre 1982.

Pérez Zevallos Juan Manuel, "El gobierno indígena colonial en Xochimilco (siglo XVI)", en Historia Mexicana, vol. XXXIII, n. ${ }^{\circ}$ 4, México D. F., El Colegio de México, 1984.

Rossend Rovira Morgado, Rossend. "De valeroso quauhpilli a denostado quauhtlahtoani entre los tenochcas: Radiografía histórica de don Andrés de Tapia Motelchiuhtzin", en Estudios de Cultura Náhuatl, vol. 45, México D. F., Instituto de Investigaciones Históricas-Universidad Nacional Autónoma de México, enero-junio 2013.

Rovira Morgado Rossend. "Elites locales y economía política en la Mesoamérica Posclásica: el caso de Molango (señorío de Metztitlán)", en Revista de Indias, vol. LXX, n. ${ }^{\circ} 249$, Madrid, Consejo Superior de Investigaciones Científicas, mayo-agosto 2010 b.

Rovira Morgado Rossend. "Huitznáhuac: ritual político y administración segmentaria en el centro de la parcialidad de Teopan (México-Tenochtitlan)", en Estudios de Cultura Náhuatl, vol. XLI, México D. F., Instituto de Investigaciones Históricas-Universidad Nacional Autónoma de México, 2010a.

Sánchez Santiró, Ernest. "El nuevo orden parroquial de la Ciudad de México: población, etnia y territorio (1768-1777)", en Estudios de Historia Novohispana, vol. 30, México D. F., Instituto de Investigaciones Históricas-Universidad Nacional Autónoma de México, enero-junio 2004.

Sanders, William T. "Cultural Ecology of the Maya Lowlands. Part I", en Estudios de Cultura Maya, vol. 2, México D. F., Instituto de Investigaciones FilológicasUniversidad Nacional Autónoma de México, 1962. 
Santamarina, Carlos. El sistema de dominación azteca: el imperio tepaneca, (Tesis de doctorado), Facultad de Geografía e Historia-Universidad Complutense de Madrid, 2006.

Smith, Michael E. "City Size in Late Postclassic Mesoamerica”, en Journal of Urban History, vol. XXXI, n. ${ }^{\circ}$, Thousand Oaks, Thompson Reuters, mayo 2005.

Torre Villalpando, Guadalupe de. "Las calles de agua de la ciudad de México en los siglos XVIII y XIX”, en Boletín de monumentos históricos del INAH, Tercera Época, n. ${ }^{\circ}$ 18, México D. F., Instituto Nacional de Antropología e Historia, enero-abril 2010, pp. 58-71.

Van Zantwijk, Rudolf. "La organización de once guarniciones aztecas: una interpretación de los folios 17v y 18 del Códice Mendocino”, en Journal de la Société des Américanistes, vol. LVI, n. ${ }^{\circ}$ 1, París, Société des Américanistes, 1967.

Villalonga, Anabel. "El imperialismo hidráulico de los aztecas en la Cuenca de México", en Tecnología del Agua, vol. XXVII, n. ${ }^{\circ} 288$, Barcelona, Reed Business Information, 2007.

Zeecaert, Leonardo. "Foundation Design and Behaviour of the Tower Latino Americana in Mexico City", en Geotechnique, vol. VII, n. ${ }^{\circ}$, Londres, Institute of Civil Engineers, 1957.

\section{Otros}

Filsinger, Tomás. Atlas y vistas de la Cuenca, Valle, Ciudad y Centro de México a través de los siglos XIV al XXI. México D.F.: Cooperativa Cruz Azul, 2005. [CD-Rom interactivo]. 